\title{
Midlatitude Fronts and Variability in the Southern Hemisphere Tropical Width
}

\author{
IRINA RUDEVA ${ }^{\mathrm{a}}$ \\ School of Earth Sciences, The University of Melbourne, and Bureau of Meteorology, Melbourne, Victoria, Australia, and \\ Shirshov Institute of Oceanology, Russian Academy of Sciences, Moscow, Russia \\ IAN SIMMONDS ${ }^{\mathrm{b}}$ \\ School of Earth Sciences, The University of Melbourne, Melbourne, Victoria, Australia \\ DAVID CROCK \\ Bureau of Meteorology, Brisbane, Queensland, Australia \\ GHYSLAINE BOSCHAT ${ }^{\mathrm{c}}$ \\ The ARC Centre of Excellence for Climate Extremes and the School of Earth, Atmosphere and Environment, \\ Monash University, Clayton, Victoria, Australia
}

(Manuscript received 18 November 2018, in final form 19 August 2019)

\begin{abstract}
This study examines the relationship between midlatitude synoptic activity and variations in the width of the tropics in the Southern Hemisphere for the period 1979-2016. The edge of the tropical belt is defined here in terms of the latitude of the subtropical ridge (STR) of sea level pressure, and eddy activity in the midlatitudes is characterized by the behavior of atmospheric fronts. It is shown that the location and intensity of the STR are significantly correlated with the number of cold fronts between $20^{\circ}$ and $40^{\circ} \mathrm{S}$ and that these relationships exhibit seasonal and zonal asymmetry. The link between the STR and the number of fronts is analyzed in five sectors of the Southern Hemisphere to reveal regional differences in their behavior and relationship with the southern annular mode. Some earlier studies on the widening of the tropics suggest that such changes may be caused by a shift in the location of midlatitude eddies. Our analysis explores the connection between these on a synoptic time scale. It shows that the variability of the width of the tropics is indeed strongly influenced by changes in the midlatitude synoptic activity, and that changes in synoptic activity lead those in the edge of the tropical belt by approximately one day.
\end{abstract}

\section{Introduction}

Earth's net radiation varies relatively smoothly from positive values in the tropics to negative values in the polar regions. In quasi-steady state the net poleward flux of energy must therefore also vary slowly with latitude. The poleward energy transport required to balance the global distribution of net radiation is predominantly brought about by the Hadley circulation

\footnotetext{
a ORCID: 0000-0001-9851-8198.

b ORCID: 0000-0002-4479-3255.

c ORCID: 0000-0002-5174-1170.
}

Corresponding author: Irina Rudeva, irina.rudeva@bom.gov.au
(HC) in the tropics and by baroclinic transient eddies in the extratropics (Randall 2015). The HC brings about an equatorward flux of sensible and latent heat, which is compensated for by a large export of potential energy (Trenberth and Stepaniak 2003) resulting in a net poleward flux of moist static energy. In the extratropics, particularly in the storm track regions, the baroclinic disturbances transport both dry static energy and latent heat poleward. Hence, although the nature of the transport mechanisms in the tropics and extratropics differ greatly, they provide a "seamless" poleward moist static energy transport to compensate for the latitudinal changes in the net radiation (Trenberth and Stepaniak 2004), indicating an intimate connection between the $\mathrm{HC}$ and extratropical eddy activity 
(see, e.g., Byrne and Schneider 2016; Singh and Kuang 2016; Singh et al. 2017; Mbengue and Schneider 2017, 2018; Baker et al. 2018; Staten et al. 2018; Zurita-Gotor and Álvarez-Zapatero 2018).

The aim of this paper is to further explore the variations in the Southern Hemisphere (SH) tropical width and midlatitude eddies and the interactions between them. The tropical width is defined here in terms of the latitude of the subtropical ridge (STR), which has been shown to be a reliable metric of the width of the tropical belt in the SH (Waugh et al. 2018). Unlike most related investigations, we here take a quasi-Lagrangian approach by characterizing the midlatitude eddies in terms of frontal structures over the hemisphere. The midlatitude fronts, which extend into lower subtropical latitudes, are, quite literally, at the interface between the tropics and the midlatitudes, and their presence and structure are central to providing the requisite poleward energy fluxes in the subtropics (Simmonds et al. 2012). Tamarin and Kaspi (2017) and TamarinBrodsky and Kaspi (2017) have recently demonstrated the power of the quasi-Lagrangian perspective in exploring global energy transports. In their case they dealt with cyclones, which provided very valuable insights. However, for the most part, cyclones and their storm tracks are located in the middle to high latitudes, while their associated frontal systems extend into the transition region mentioned above. In this sense, our analysis of fronts offers a more targeted approach to eddy transport for this investigation.

We chose to study the $\mathrm{SH}$ in this context for a number of reasons. First, observed changes in the SH tropical width are much less zonally asymmetric than in the Northern Hemisphere (NH; Grise et al. 2018; Staten et al. 2018), so the SH presents a less complex environment for testing ideas on front-tropical width interactions. Also, the southern tropical belt appears to present a robust response to stratospheric ozone loss (Birner et al. 2014; Staten et al. 2018). In addition, the tropical-extratropical transition region is subject to the variations in weather and climate brought about by changes in the disposition of the fronts and the STR. In particular, fronts bring precipitation to the southern parts of Australia and Africa (Timbal and Drosdowsky 2013; Hope et al. 2014; Raut et al. 2017; Blázquez and Solman 2018) and, hence, small meridional shifts in their northern extremity can potentially result in large and influential precipitation changes. Meanwhile, the southern parts of Australia and Africa have already undergone significant precipitation reductions in recent decades (Risbey et al. 2009; MacKellar et al. 2014; Cai et al. 2012; Cai and Cowan 2013; Frederiksen and Grainger 2015; Solman and Orlanski 2016; Turton 2017).
The STR influence on Australian climate was neatly illustrated in winter 2017 (although not included in the analysis). In that season the STR was both stronger and farther south than usual for this time of year. As stated in the Monthly Weather Review (June and July 2017) produced by the Bureau of Meteorology (http://www.bom. gov.au/climate/mwr/; not the Monthly Weather Review published by the American Meteorological Society), this resulted in the second-driest June on record for Australia as a whole, and the driest on record for large areas of southern Australia; July 2017 rainfall was also below average and associated with a lack of cold fronts crossing southern Australia.

Our hypothesis is that synoptic processes in the midlatitudes lead the changes in the tropical width. This supposition is tested on the subdaily time scale, which offers a more insightful perspective on their lead-lag relationship. In section 2 we describe the methods and dataset used, including the description of the tropical width and regional southern annular mode (SAM) indices. Section 3 presents the results from correlation analyses between STR characteristics and number of fronts along with an evaluation of the role of SAM in changes of the tropical width. Then, lag correlation is used to reveal the time relationship between changes in tropical width and frontal activity. To better understand the interaction between the eddies in the midlatitudes and the $\mathrm{HC}$, we perform our analysis at the synoptic time scale. Using 6-hourly analyses, rather than, for example, monthly averages, will provide new insight into the behavior of the abovementioned variables and their relationship as metrics derived at different temporal resolutions can be systematically different. One of the rationales for the analysis using high-frequency data was that the processes of meridional energy transports are nonlinear. This is especially true in the extratropics where transient systems abound. In the last section conclusions are drawn on the variability of STR intensity and position and how these characteristics are associated with the synoptic systems in the midlatitudes.

\section{Methods and data}

The analysis we present in this paper is based on the quantification of properties and behavior of fronts and of the STR. In this section we first review the methods of frontal identification used in previous studies [section $2 \mathrm{a}(1)$ ] and then present a more detailed description of the method that was selected for this study [section 2a(2)]. Similarly, sections $2 \mathrm{~b}(1)$ and $2 \mathrm{~b}(2)$ describe metrics to define the tropical width. The southern annular mode (SAM) and data are discussed in sections $2 \mathrm{c}$ and $2 \mathrm{~d}$, respectively. 


\section{a. Frontal identification methods and their application to diagnosing variability}

\section{1) REVIEW OF FRONTAL IDENTIFICATION METHODS}

In analyzing atmospheric fronts, it is important to keep in mind that there is no single unambiguous quantitative definition for them. Although various schemes produce broadly consistent results, there are some important differences. For example, Schemm et al. (2015) compared a thermal frontal identification approach (relying on the gradient of equivalent potential temperature) with one based on wind structure and found them to exhibit marked differences in certain regions. They pointed out that the thermal approach shifts the areas of frontal activity equatorward compared to the wind-structure method, and commented that the potential temperature gradient can be dominated by moisture gradients, which results in the detection of several quasi-stationary fronts in the tropics and coastal regions. Other recent algorithms have used combinations of both thermodynamic and dynamic parameters (Parfitt et al. 2017; Blázquez and Solman 2018), and other approaches (Crespo et al. 2017; Spensberger and Sprenger 2018).

Many reanalysis-based studies indicate that there has been a poleward shift in the mean latitude of SH extratropical fronts and cyclones, with fewer systems in the subtropics and more at high southern latitudes over the recent decades (e.g., Simmonds and Keay 2000; Pezza et al. 2007, 2012; Solman and Orlanski 2014; Rudeva and Simmonds 2015). [The analysis of Grieger et al. (2018) found the increase in the number of subantarctic cyclones to be largely independent of the cyclone identification method employed.] In contrast, Berry et al. (2011) reported a decrease in front frequency poleward of $60^{\circ} \mathrm{S}$ and an increase equatorward of that latitude [based on 21 years of data (1989-2009)]. Using an algorithm constructed on gradients of wet bulb potential temperature, they diagnosed significant positive trends in subtropical fronts. As mentioned above, these fronts tend to be strongly associated with moisture gradients, and, hence, are more likely to be identified in such schemes compared to those using more dynamic parameters. It could be argued that positive trends in subtropical fronts identified in their analysis are, to a significant extent, reflective of a warmer (and, hence, moister) atmosphere.

Climate model simulations are consistent with the majority of the above observational studies, with the tendency to poleward displacement of synoptic systems in the twenty-first century (see Collins et al. 2013;
Kirtman et al. 2013). Catto et al. (2014) found in models from phase 5 of the Coupled Model Intercomparison Project (CMIP5; Taylor et al. 2012) the $\mathrm{SH}$ poleward shift of the frequency maximum to be most marked in the Indian Ocean sector of the Southern Ocean. Tamarin-Brodsky and Kaspi (2017) suggested a summer poleward shift of the cyclone track density of $4.9^{\circ}$ latitude by the end of this century, and highlighted a notable increase in track density between $55^{\circ}$ and $65^{\circ} \mathrm{S}$. Very marked in their results (see their Fig. 1g) is an increase in cyclone genesis between $60^{\circ}$ and $70^{\circ} \mathrm{S}$ in response to the simulated shift in baroclinicity. Consistent with this, Chang (2017) found in the CMIP5 outputs a significant increase in extreme cyclones around most of the periphery of the Antarctic. He showed this result to be essentially independent of the cyclone identification methods used and how the extremes were defined.

\section{2) Frontal IDENTIFICATION METHOD USED IN PRESENT ANALYSIS}

We identified atmospheric fronts using the comprehensive scheme of Simmonds et al. (2012) and Rudeva and Simmonds (2015). This Eulerian approach is based on the wind shift along the frontal line: that is, in the $\mathrm{SH}$ the wind shifts from northwest to southwest quadrants as a meridionally elongated cold front is passing a grid point. The algorithm also requires that between sequential 6-hourly analyses the increase in the meridional wind component should exceed $2 \mathrm{~m} \mathrm{~s}^{-1}$ [for more detailed discussion on the parameter settings see Schemm et al. (2015)]. This simple dynamical approach works well for frontal identification, particularly in the SH (Schemm et al. 2015), and shows robust results compared to other approaches that rely on the gradient of equivalent potential temperature, as was discussed earlier (section 2a). However, the wind-based scheme applied here can only capture meridionally elongated fronts that are mainly cold fronts.

\section{b. Metrics of tropical width and their associated temporal variabilities}

\section{1) REVIEW OF TROPICAL WIDTH METRICS}

A broad range of tropical edge latitude diagnostics have been employed in the literature. These include aspects of tropopause height, metrics that relate directly to airflow patterns [e.g., the zero-crossing latitude of the mass transport streamfunction (PSI) and velocity potential] or can be directly derived from observations (e.g., thermal infrared radiation, ozone), as well as precipitation-evaporation difference. These have been used, and in some cases compared, in the 
most recent studies of Singh et al. (2017), Schmidt and Grise (2017), Son et al. (2018), Baker et al. (2018), Nguyen et al. (2018, hereinafter NG2018), Staten et al. (2018), and Grise et al. (2018, 2019).

Davis and Rosenlof (2012) found that the edge definition strongly influenced the deduced magnitudes of tropical expansion. They made the argument that the differences in the expansion rates were a result of the differing physics represented by the various diagnostics. Their results reveal the importance of understanding what processes are driving observed and future changes in the tropical width. Solomon et al. (2016) found the width of the tropics, defined from the commonly used measure based on zero crossing of the PSI, to be strongly correlated with the midlatitude jet, but essentially uncorrelated with the upper atmospheric metrics they explored, in line with conclusions from Davis and Birner (2017) and Waugh et al. (2018). The inferences drawn by Davis et al. (2018), using total column ozone, were similar, even after they removed a spurious jump in the data. In the multimetric analysis of Grise et al. (2018) the PSI-based metric suggested a strong tropical expansion in summer and autumn. Such trends, apparent during summer and autumn in both hemispheres, were at considerable variance from the trends in the other metrics they examined. They commented that this discrepancy likely reflects the difficulty in defining the streamfunction during these warm seasons [see also Grise and Polvani (2016)].

Studies conducted over the last two decades have estimated rates of tropical expansion from barely detectable $\left(0.2^{\circ}\right.$ latitude per decade) to very rapid $\left(2^{\circ}\right.$ latitude per decade) (Grise et al. 2018). The reasons for this diversity are now becoming clearer. As indicated above, these diagnosed rates are sensitive to the metric used, as well as to the period of data analyzed. Staten et al. (2018) remarked that near the beginning of the satellite era, the early 1980s saw an anomalously equatorward SH edge of the tropics, and 2010 exhibited an anomalously poleward edge. Hence, observational studies performed in 2010s were primed by chance to show large trends in tropical width (e.g., D'Agostino and Lionello 2017). Various studies have suggested that the larger rates of tropical widening in some reanalyses are likely to be unreliable (Quan et al. 2014; Allen and Kovilakam 2017). Natural variability is also known to have a significant impact on the location of the edge of the tropical belt. For example, the tropics widen during strong La Niña events and in the positive phase of the SAM, and vice versa (Nguyen et al. 2013; Lucas and Nguyen 2015). Grise et al. (2019) concluded that both natural variability and human activities (through increasing greenhouse gases and stratospheric ozone depletion) have likely contributed to a poleward shift of the $\mathrm{SH}$ tropical edge.

Model studies are proving to be very useful in understanding the variability of the tropical extent over recent decades, and in highlighting the roles of anthropogenic influences on poleward expansion (Tao et al. 2016). Much has been written on the apparent underestimation of tropical expansion rates by the CMIP5 models. In this context some authors have pointed to the potential shortcomings of models (Maher and Sherwood 2016; NG2018), while others have referred to the influence of deficiencies in reanalyses (Birner et al. 2014; Allen and Kovilakam 2017). Using a suite of climate model simulations, Allen and Kovilakam (2017) were led to conclude that most of the poleward excursion is due to unforced sea surface temperature (SST) variability, primarily related to recent ENSO/interdecadal Pacific oscillation (IPO) variability and its shift from the warm to cold phase. Similar conclusions were reached by Mantsis et al. (2017) and Amaya et al. (2018), who remarked that longer-term expansion of the tropics is likely to be significantly less than in recent decades as the IPO returns to its warm phase. The swing of the IPO from the warm to cold phase is not captured in the ensemble members of the historical CMIP5 simulations (Newman et al. 2016), which appears to offer a plausible hypothesis to explain the climate models' underestimation of the "observed" tropical expansion. The recent comprehensive analysis of Grise et al. (2018) confirmed that the vast majority of the recent seasonal SH trends in tropical width do not exceed the range of natural variability exhibited by global climate models. That is, overall, there is no indication that global climate models are systematically unable to capture the magnitude of the observed SH trends.

\section{2) TROPICAL WIDTH METRIC USED IN THIS STUDY}

To define the edge of the tropical belt, we take the latitude of the STR, which reflects the subtropical subsidence of the HC. This robust and simple measure has been used in many studies of the SH circulation (Timbal and Drosdowsky 2013; Choi et al. 2014; Kim et al. 2017; Grise et al. 2018). The STR metric, as discussed in detail below, is closely related to the latitude at which the mean zonal (near) surface wind transitions from tropical easterlies to extratropical westerlies (Shaw and Voigt 2016; Singh et al. 2017; Grise et al. 2018). As discussed by Timbal and Drosdowsky (2013), the ridge has intensified significantly over the last century accompanied by a southward shift of the SH midlatitude storm track (Fyfe 2003; Hope et al. 2006; Pezza et al. 2007). Li et al. (2012) also identified poleward shifts of the STR over longitudes $110^{\circ}-150^{\circ} \mathrm{E}$, and found these to be related to 
a) DJF

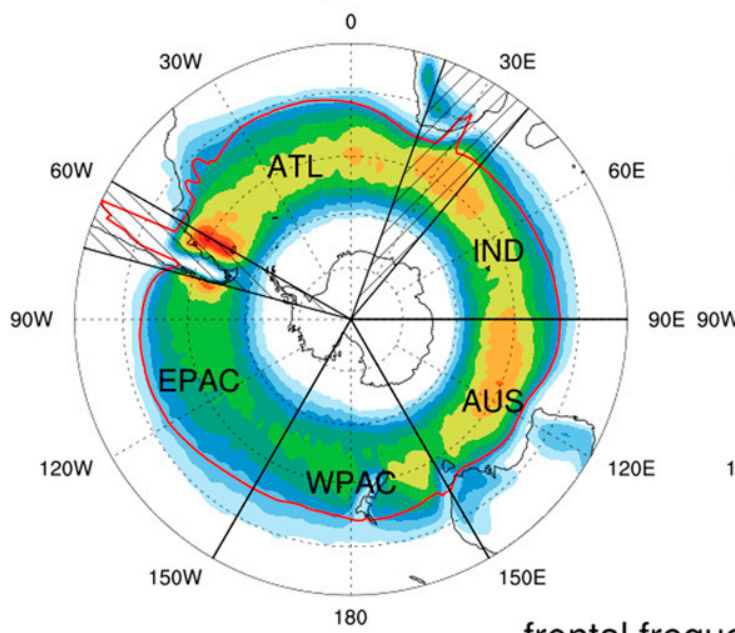

b) JJA

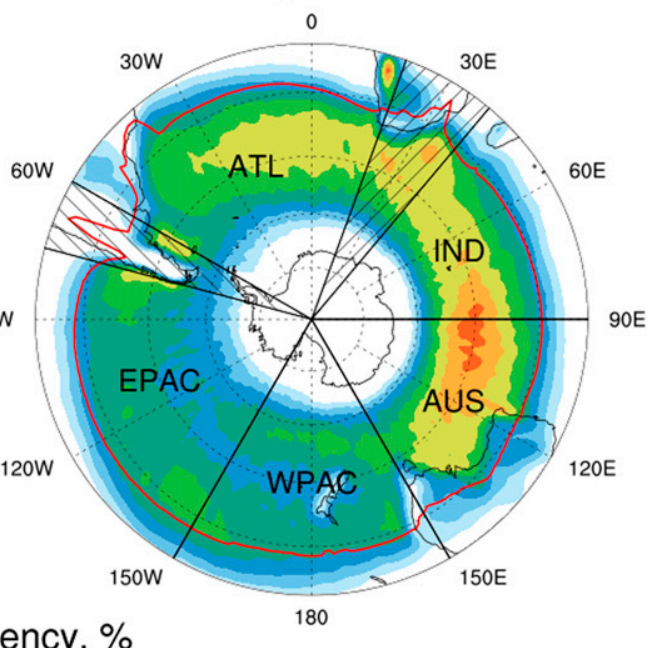

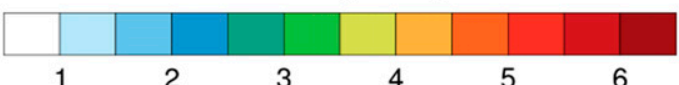

FIG. 1. Climatological frontal frequency (colors; \%), calculated as frequency of frontal points (in percent) at each grid point, in (a) DJF and (b) JJA averaged over a 30-yr period (1980-2009 and 1979-2008, respectively). The framed areas show the five selected longitude sectors: ATL $\left(60^{\circ} \mathrm{W}-20^{\circ} \mathrm{E}\right)$, IND $\left(30^{\circ}-90^{\circ} \mathrm{E}\right)$, AUS $\left(90^{\circ}-\right.$ $\left.150^{\circ} \mathrm{E}\right)$, WPAC $\left(150^{\circ} \mathrm{E}-150^{\circ} \mathrm{W}\right)$, and $\mathrm{EPAC}\left(150^{\circ}-75^{\circ} \mathrm{W}\right)$. The areas remaining between these regions are hatched. The red line shows the climatological STR position for the corresponding season.

rainfall reductions over Australia and to be instigated by the warming SSTs in the tropical Indian-western Pacific Oceans. Model simulations indicate that the STR intensity will increase over the coming century while its mean position will be farther south in the SH (Kent et al. 2013).

In this study the STR is taken as the maximum of the 6-hourly meridional mean sea level pressure (MSLP) profiles between $9^{\circ}$ and $45^{\circ} \mathrm{S}$. Longitudinal-sector means of MSLP are calculated for the whole hemisphere and across five SH longitude sectors (Fig. 1), namely the Atlantic (ATL; $\left.60^{\circ} \mathrm{W}-20^{\circ} \mathrm{E}\right)$, Indian (IND; $30^{\circ}-90^{\circ} \mathrm{E}$ ), Australian (AUS; $90^{\circ}-150^{\circ} \mathrm{E}$ ), western Pacific (WPAC; $150^{\circ} \mathrm{E}-150^{\circ} \mathrm{W}$ ), and eastern Pacific (EPAC; $150^{\circ}-75^{\circ} \mathrm{W}$ ) sectors. The studies that have previously investigated STR characteristics usually defined STR in a particular longitude band, such as the Australian region (Drosdowsky 2005; Williams and Stone 2009; Timbal and Drosdowsky 2013; Kent et al. 2013; Whan et al. 2014). Choi et al. (2014) performed STR analysis at $5^{\circ}$ longitude bands across the whole circle of latitude in both Northern and Southern Hemispheres; however, STR characteristics for separate ocean basins have received little attention in the past. Following Drosdowsky (2005) and Kent et al. (2013), two parameters representing characteristics of the STR are used in this study: the intensity (STRI) and the latitude (or position-hence called STRP) of the maximum in the MSLP profile.

\section{c. $S A M$}

The SAM is the dominant mode of atmospheric variability in the extratropical $\mathrm{SH}$ and owes its existence to internal atmospheric dynamics in the midlatitudes (Thompson and Wallace 2000). Due to its importance for the SH circulation, the potential influence of the SAM is considered when exploring the relationship between midlatitude eddies and the STR characteristics. Various methods can be used to define the SAM index, including an EOF-based approach (see, e.g., Thompson and Wallace 2000; Purich et al. 2013), a procedure using station data (Marshall 2003), and the Gong and Wang (1999) method based on gridpoint analyses; it is the last of these that is applied in this study.

For our analysis there is potential value to be gained from defining "regional" SAMs (much in the same way that the North Atlantic Oscillation represents a regional Arctic Oscillation). Meneghini et al. (2007) initiated this idea and found it to provide insights into rainfall variability over Australia. Here we define regional SAM indices that are calculated for the five longitude sectors defined above.

For the SAM index, we use the normalized difference between the zonally averaged monthly deviation of MSLP from the climatological mean between $40^{\circ}$ and $65^{\circ} \mathrm{S}$ (Gong and Wang 1999): 
a) annual

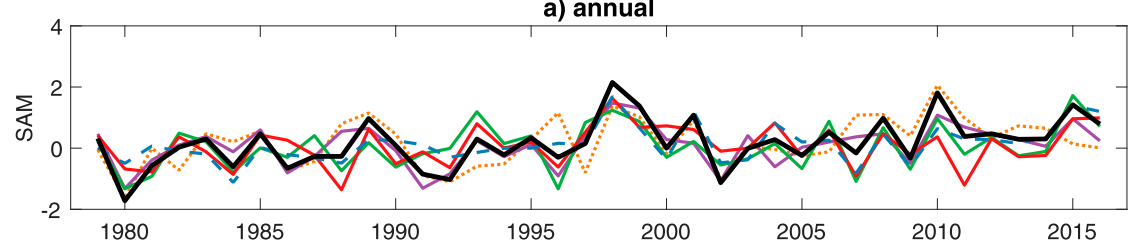

b) DJF

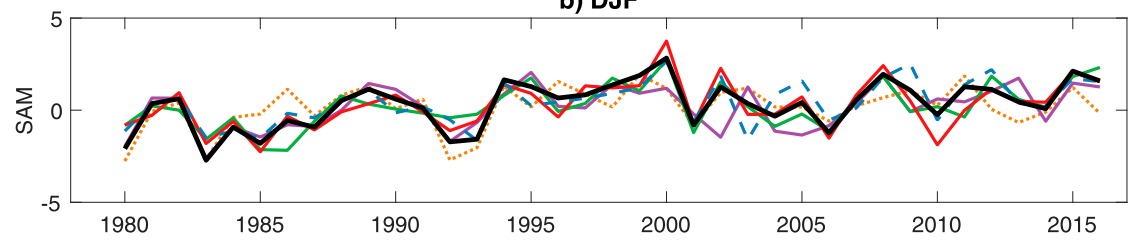

c) MAM

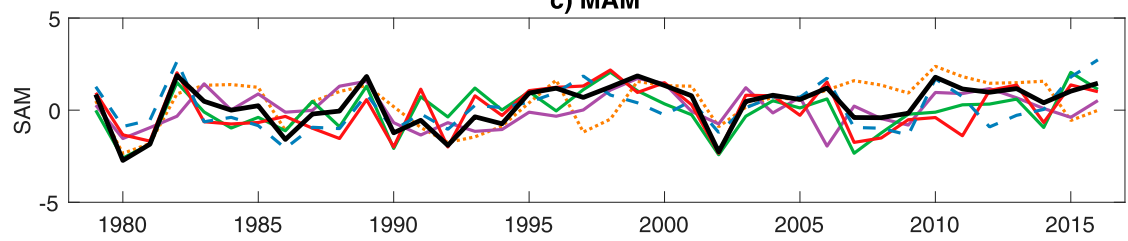

d) JJA

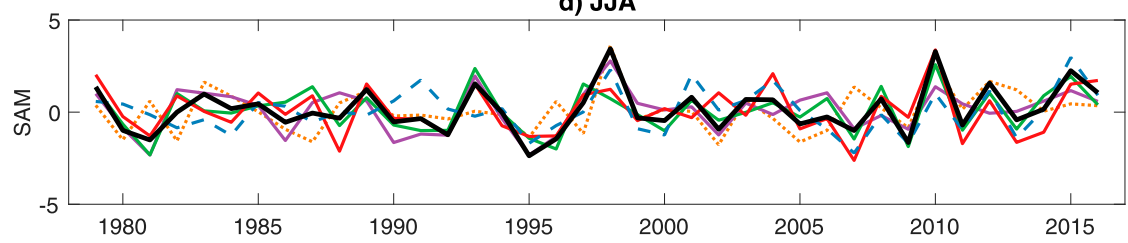

e) SON

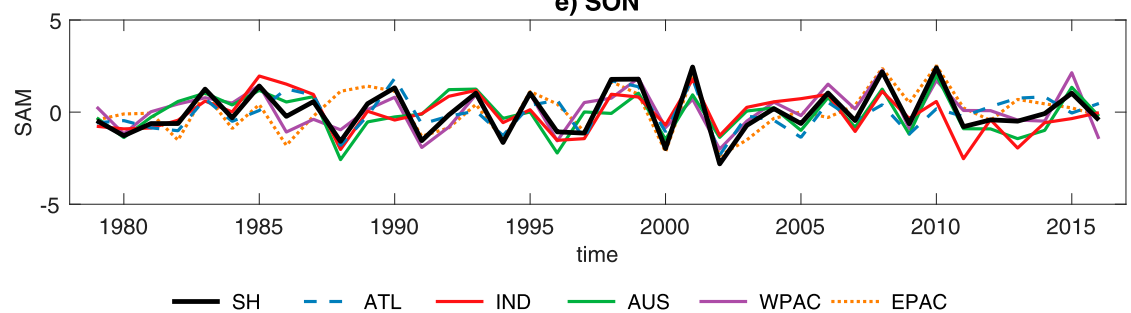

FIG. 2. The SH and regional SAM time series. These time series were calculated as normalized differences between the regionally and zonally averaged monthly MSLP between $40^{\circ}$ and $65^{\circ} \mathrm{S}$.

$$
\mathrm{SAM}=\frac{\overline{\mathrm{MSLP}}_{40}-\left[\overline{\mathrm{MSLP}_{40}}\right]}{\sigma_{40}}-\frac{{\overline{\mathrm{MSLP}_{65}}}_{6}\left[\overline{\mathrm{MSLP}_{65}}\right]}{\sigma_{65}},
$$

where the overbar indicates monthly mean, the square brackets stand for the climatological mean for a selected longitude range, and $\sigma$ denotes the MSLP standard deviation at the indicated latitude. The 30 -yr period from 1979 to 2008 is used for the climatological mean and normalization. Seasonal or annual SAM indices are calculated by averaging the corresponding monthly SAM indices.

\section{d. Data}

We use the ERA-Interim data [i.e., the European Centre for Medium-Range Weather Forecasts interim reanalysis described by Dee et al. (2011)], generally regarded as being the most reliable reanalysis product over the extratropical SH. Hodges et al. (2011) and Tilinina et al. (2013) showed that ERA-Interim has considerable skill in representing synoptic systems in recent decades.

The analysis is performed over the 38-yr period from 1979 to 2016 using 6-hourly MSLP. The horizontal resolution used for frontal identification is $1.5^{\circ} \times 1.5^{\circ}$, and $0.125^{\circ}$ horizontal resolution was used for the STR identification.

\section{Results}

\section{a. SH and regional SAM indices}

Figure 2 shows the time series of five regional SAM indices along with the SH SAM. As one would expect 
the annual SH SAM index is fairly highly correlated with regional indices, especially in the WPAC sector where the correlation coefficient $r$ with the SH SAM reaches 0.86 (Table 1). The lowest $r$ is found in the IND sector (0.65). Interestingly, during the season of peak correlations between regional and hemispheric SAM indices [in December-February (DJF)], the IND region demonstrates the highest $r$ values (0.87). The lowest seasonal $r$ values are found in the ATL, reaching 0.40 in DJF. On the contrary, the Australian sector SAM is closely aligned with the SH SAM throughout the year. In the Pacific the correlation coefficient drops to 0.57 in the WPAC during autumn [March-May (MAM)] and 0.62 in EPAC during winter [June-August (JJA)]. Spring [September to November (SON)] $r$ values remain relatively high in all sectors, pointing to a more zonal circulation in that season. Associations between regional and the zonal-mean SAM confirm the asymmetric behavior of the eastern and western hemispheres found earlier by Ding et al. (2012), thereby suggesting that a regional SAM approach will be insightful, particularly in the colder seasons.

\section{b. STR position and intensity}

We next examine the location and intensity of the STR (Fig. 3). The annual-mean latitude of the STR ranges between $31^{\circ}$ and $34^{\circ} \mathrm{S}$, with a more equatorward position in the ATL and EPAC sectors and more poleward in the IND and AUS sectors. The largest variations in the STR position are observed in the WPAC, possibly due to the role of the Walker circulation in promoting the expansion and/or contraction of the HC in that region (Amaya et al. 2018).

A comparison of the STR position with the location of the tropical edge defined using PSI reveals that the latter is located a few degrees farther north (at $28^{\circ} \mathrm{S}$; NG2018, see their Fig. 3). This difference can be explained by the fact that NG2018 defined the tropical edge by using the $25 \%$ peak value of the PSI between 700 and $400 \mathrm{hPa}$. If the width of the tropics were defined at the point where the PSI changes sign (a more commonly used indication of the HC edge; e.g., Oort and Yienger 1996), the difference with our estimates would have been smaller (see Fig. 2 in NG2018). In their regional perspective, the PSI tropical edge shows much larger variations than the STR, reaching $10^{\circ} \mathrm{S}$ in the American sector $\left(140^{\circ}-20^{\circ} \mathrm{W}\right), 20^{\circ}-25^{\circ} \mathrm{S}$ in the African sector $\left(20^{\circ} \mathrm{W}-65^{\circ} \mathrm{E}\right)$, and $35^{\circ} \mathrm{S}$ in the Asian-Pacific sector.

The STR position varies seasonally between $25^{\circ}-30^{\circ} \mathrm{S}$ in winter and $33^{\circ}-40^{\circ} \mathrm{S}$ in summer (Figs. 3a-e). In summer, the AUS STR position is more poleward than the zonal average, possibly due to the strong meridional temperature gradient in this sector (Kidston et al. 2009). In contrast, the summer ATL STR position is closer to
TABLE 1. Correlation coefficients between SH and regional SAM indices at the annual and seasonal time scales. Correlations shown in regular font are significant at $p<0.01$; those in italics are significant at $p<0.05$.

\begin{tabular}{lccccc}
\hline \hline & ATL & IND & AUS & WPAC & EPAC \\
\hline Annual & 0.76 & 0.65 & 0.73 & 0.86 & 0.73 \\
DJF & 0.40 & 0.87 & 0.82 & 0.78 & 0.80 \\
MAM & 0.41 & 0.71 & 0.74 & 0.57 & 0.70 \\
JJA & 0.56 & 0.73 & 0.81 & 0.77 & 0.62 \\
SON & 0.59 & 0.68 & 0.73 & 0.83 & 0.76 \\
\hline
\end{tabular}

the equator than the zonal average. Table 2 shows correlation values between the zonally averaged STR and regional STR positions on annual and seasonal time scales. We find notably high correlation values in AUS and WPAC during summer, where the large meridional shifts dominate the zonally averaged STR position. Conversely, a more zonally symmetric circulation in the IND region (Ding et al. 2012) means that the STR position shows lower seasonal variability in that region.

The annual (hemispheric) STR intensity (Figs. 3f-j) is on average $1018 \mathrm{hPa}$, and ranges from $1020-1022 \mathrm{hPa}$ in the IND sector to $1015-1017 \mathrm{hPa}$ in the WPAC sector. On a seasonal scale, the lowest values of intensity are observed in austral summer (between 1015 and $1020 \mathrm{hPa}$ in all sectors) and the highest are reached in winter (particularly in the IND sector, where the STRI exceeds $1025 \mathrm{hPa}$ in some years; Figs. 3g,i). It can be speculated here that the higher IND STRI can be explained by the prevalence of a more zonally symmetric circulation in the Indian Ocean. Interestingly, the correlation between SH and regional STR intensity is significantly higher in both Pacific regions (WPAC and EPAC) compared to the other three regions of the SH (Table 3).

\section{c. Number of fronts and its association with tropical width and SAM}

The climatology of fronts for summer (DJF) and winter (JJA), calculated as the frequency of frontal points (in percent) at each grid point, is shown in Fig. 1. [Note that these plots show the frequencies of all frontal points, not just their center of gravity as in Simmonds et al. (2012).] The highest frontal frequencies in DJF are observed in a belt between $40^{\circ}$ and $60^{\circ} \mathrm{S}$ with regional maxima east of Patagonia, southeast of South Africa, and southwest of Australia. In winter, the belt of maximum frontal activity widens to the low midlatitudes starting from $30^{\circ}$ to $60^{\circ} \mathrm{S}$, with the maximum number of fronts observed in the western Indian Ocean. Meanwhile in the Pacific there are indications of two separate storm tracks associated with the subtropical and polar jets. This figure illustrates well the intimate link between the location of fronts and the 
a) STRP, annual

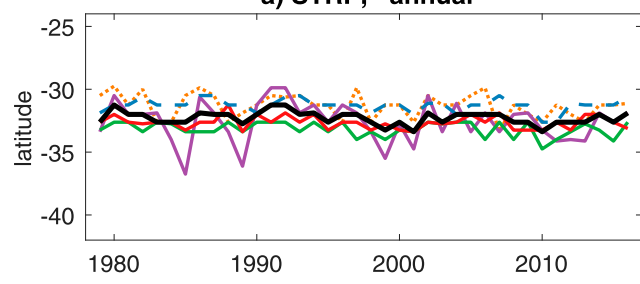

b) DJF

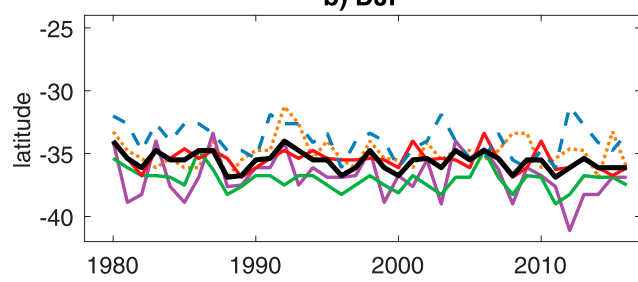

c) MAM

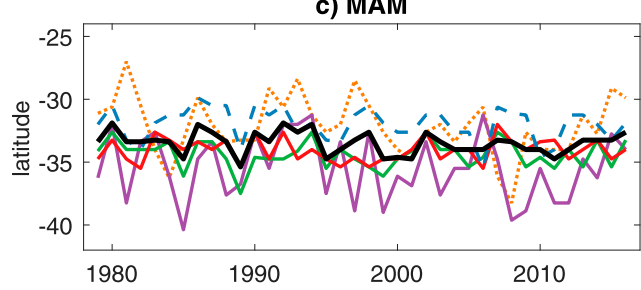

d) JJA

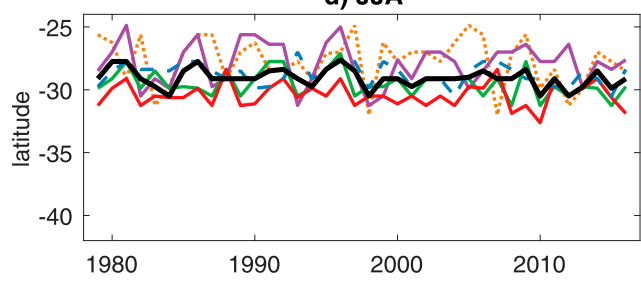

e) SON

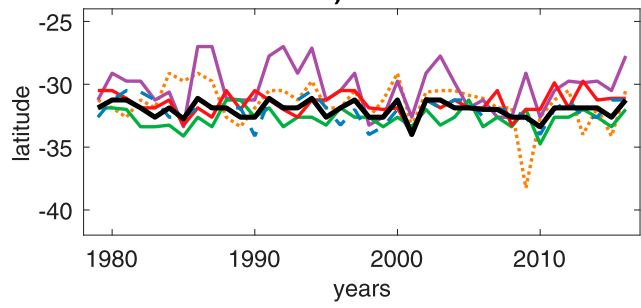

f) STRI, annual

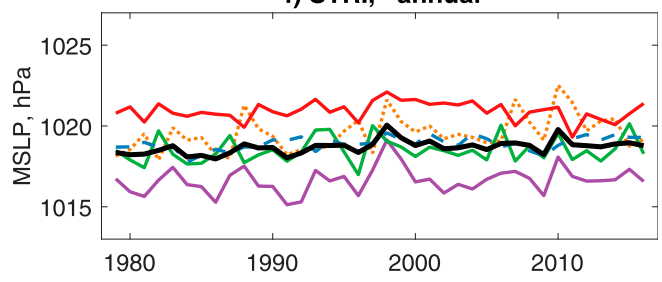

g) DJF

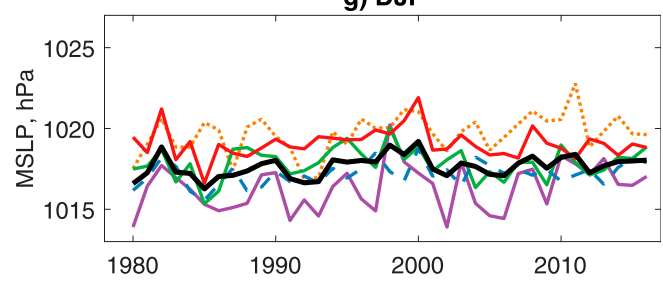

h) MAM

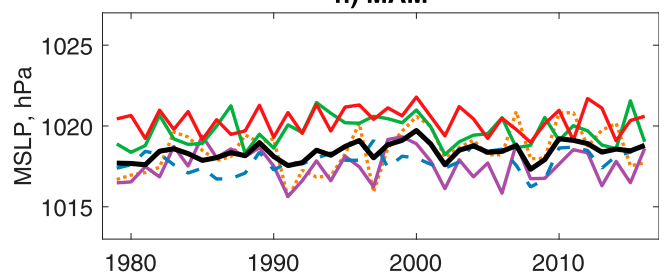

i) JJA
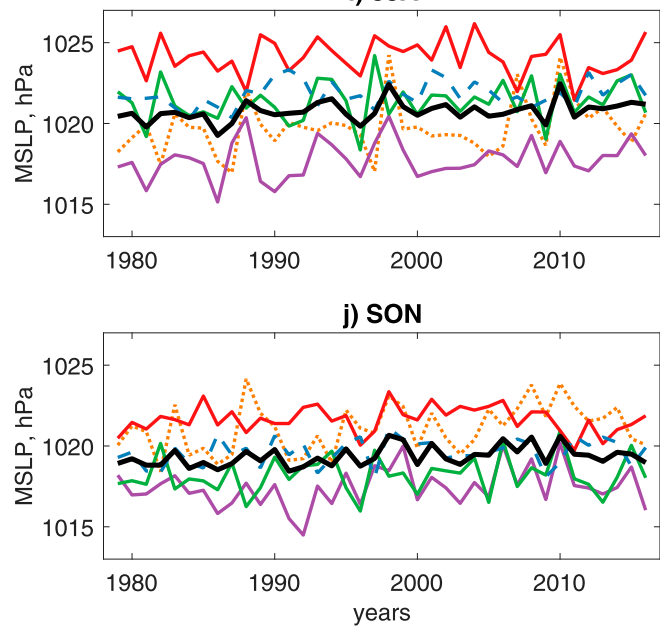

- $\mathrm{SH} \quad-\mathrm{ATL} \longrightarrow$ IND

AUS WPAC …..... EPAC

FIG. 3. The SH and regional time series of (a)-(e) position (STRP) and (f)-(j) intensity (STRI) of the subtropical ridge (STR).

position of the STR (indicated with the red line) along with the suggestion that the tropics start where midlatitude eddies stop controlling the dynamics of the atmosphere. These plots also support the choice of atmospheric fronts rather than cyclones when relating synoptic processes in the midlatitudes to the tropical width, since cyclones tend to be more active in higher latitudes (Wernli and Schwierz 2006).
Figure 4 shows the position and intensity of the $\mathrm{SH}$ STR and the number of fronts that have at least one point between $20^{\circ}$ and $40^{\circ} \mathrm{S}$. We note here that cold fronts may have an average length of up to $2000 \mathrm{~km}$ depending on their location (see Fig. 5 in Simmonds et al. 2012), and, hence, the fronts that we discuss in this section may extend well beyond the $20^{\circ}-40^{\circ} \mathrm{S}$ belt (mainly into the higher latitudes). As mentioned above, 
TABLE 2. As in Table 1, but between SH and regional STR position.

\begin{tabular}{lccccc}
\hline \hline & ATL & IND & AUS & WPAC & EPAC \\
\hline Annual & 0.48 & 0.62 & 0.53 & 0.75 & 0.50 \\
DJF & 0.51 & 0.61 & 0.72 & 0.64 & 0.44 \\
MAM & 0.57 & 0.37 & 0.64 & 0.62 & 0.37 \\
JJA & 0.44 & 0.36 & 0.53 & 0.54 & 0.56 \\
SON & 0.62 & 0.47 & 0.45 & 0.71 & 0.50 \\
\hline
\end{tabular}

the annual SH STR position is between $31^{\circ}$ and $34^{\circ} \mathrm{S}$; however, it experiences significant intraseasonal variability, reaching as far poleward as $37^{\circ} \mathrm{S}$ in some summer seasons and $28^{\circ} \mathrm{S}$ in winter. Although trends are not shown, there is a tendency for a southward shift in the STR position, particularly noticeable in DJF and JJA, which is in agreement with previous studies discussed in the introduction. The STR intensity varies from 1017$1019 \mathrm{hPa}$ in DJF to $1020-1022 \mathrm{hPa}$ in JJA and also tends to increase in JJA, although this signal is weak.

Overall, the annual and seasonal variability in frontal activity are in close agreement with the variability of the STR characteristics (Figs. 4 and 5). The correlation coefficients for the SH range between 0.6 and 0.8 (see Fig. 5) (note here that the STR intensity values have been multiplied by -1 to produce positive correlation values and assist interpretation). Interestingly, the annual number of fronts is most strongly associated with the STR intensity (see red circle in Fig. 5), although on seasonal time scales it is more generally linked to the STR position (see blue circles).

Circulation in the $\mathrm{SH}$, particularly in the extratropics, is largely dominated by the SAM. In line with the findings of Rudeva and Simmonds (2015), the number of fronts in low midlatitudes $\left(20^{\circ}-40^{\circ} \mathrm{S}\right)$ is significantly anticorrelated with the SAM (Fig. 5; correlation coefficients are shown by the black asterisks). For the zonally averaged STR, the SAM is also highly correlated with both STR characteristics. However, the relationship between the regional STR and the zonal-mean SAM is much weaker, especially in the Pacific sectors (Fig. 5, marked by stars). Thus, we make use of the regional SAM indices introduced in section 2c (Fig. 5, shown by crosses). This approach leads to stronger relationships between the SAM and both the frontal numbers and STR characteristics, particularly in autumn and winter, as was anticipated earlier. The presence of a strong regional SAM signal agrees with Ding et al. (2012), who found that the SAM-related fluctuations over the midlatitude Pacific and Indian Ocean sectors tend to behave independently (except in summer). They also suggested that the SAM signature in the Pacific resembles a Rossby wave train forced by the tropics. Our results show that the EPAC region is the most sensitive to
TABLE 3. As in Table 1, but between SH and regional STR intensity.

\begin{tabular}{lccccc}
\hline \hline & ATL & IND & AUS & WPAC & EPAC \\
\hline Annual & 0.48 & 0.32 & 0.45 & 0.86 & 0.68 \\
DJF & 0.51 & 0.64 & 0.65 & 0.74 & 0.68 \\
MAM & 0.44 & 0.51 & 0.34 & 0.58 & 0.72 \\
JJA & 0.42 & 0.31 & 0.48 & 0.69 & 0.65 \\
SON & 0.35 & $0.27^{\mathrm{a}}$ & 0.28 & 0.82 & 0.78 \\
\hline
\end{tabular}

${ }^{\mathrm{a}}$ Not significant at $p<0.1$.

the use of the regional SAM index, suggesting that the drivers of the circulation in this region differ from the rest of the $\mathrm{SH}$, possibly due to the role of the tropics.

\section{d. Multiple regression}

Encouraged by the generally high correlations between the number of fronts at $20^{\circ}-40^{\circ} \mathrm{S}$ and the STR characteristics, we performed a multiple regression analysis to establish a link between frontal activity and both the location and intensity of the STR (Fig. 6). Because adding an extra predictor to a model leads to an automatic increase in $R^{2}$, a measure of the goodness-offit of a model, the adjusted $R^{2}$ value (p. 423 in Venables and Ripley 2003) was used to evaluate whether the added parameter contributed skill over and above that which would be expected by chance.

Taking the two STR parameters into account increases the predictive skill of the model, raising the correlation coefficient to 0.82 for the annual data and 0.88 in SON (see right panels in Fig. 6). For three out of the five regions (namely, the ATL, WPAC, and EPAC sectors), multiple regression also increases the predictive skill of the model in all but one season (JJA, shown in red crosses). However, for the Australian sector the STR intensity provides little added value to the regression (except in autumn), suggesting that the STR location is more closely associated with weather in this region. This is at odds with the results of Whan et al. (2014), who found that the STR is strongly related to rainfall variability across southern Australia, with the intensity of the STR being more important than its position. In contrast to the AUS case, in the ATL sector the STR intensity appears to be more strongly related to the number of fronts than is STRP, except in winter. In the Pacific (WPAC and EPAC) STR intensity in winter, although highly correlated with the number of fronts ( 0.57 and 0.73 , respectively), does not improve the skill of the statistical model due to exceptionally high correlation found between the fronts and STR location ( 0.80 and 0.83 , respectively).

To illustrate the effect of the STR on the number of fronts over the $\mathrm{SH}$ (not only in the $20^{\circ}-40^{\circ} \mathrm{S}$ belt), we show differences between the annual average number of fronts for 10 years of most poleward and most equatorward 

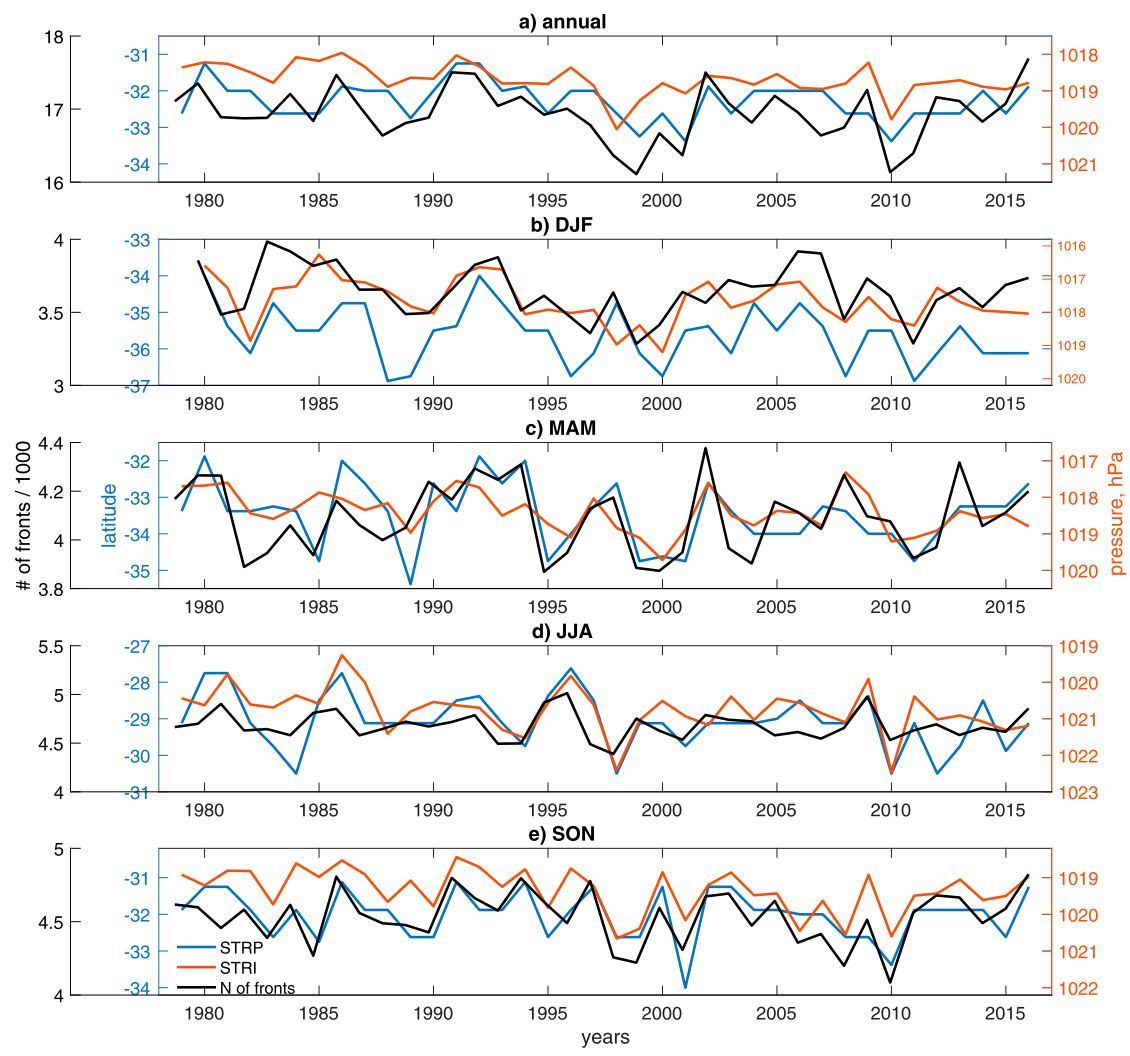

FIG. 4. (a) Annual and (b)-(e) seasonal time series of the SH STR position (blue line) and STR intensity (red line) along with the number of atmospheric fronts per season divided by 1000 between $20^{\circ}$ and $40^{\circ} \mathrm{S}$ (black line).

STR locations (Figs. 7a-c). An anomalously high (i.e., poleward) STR position is associated with a decrease in the number of fronts north of $45^{\circ} \mathrm{S}$. Interestingly, anomalously high/low positions of regional STR produce very similar responses over the whole SH (the IND region is chosen for illustration, with other sectors demonstrating similar patterns). The only exception here is the EPAC sector (Fig. 7c), which is characterized by a much stronger but, at the same time, more local response in the number of fronts mainly in the central and eastern Pacific. A similar analysis for the number of fronts during years of anomalously high and low STR intensity produces similar patterns, with even stronger anomalies in the EPAC (Figs. 7d-f). This anomaly is consistent with the weak relationships of frontal activity and STR characteristics with the zonalmean SAM found in the previous section, confirming that circulation patterns in the subtropical and extratropical Pacific differ vastly from the rest of the SH.

\section{e. Lag correlation between STR and number of fronts}

The strong correlation between the STR and midlatitude synoptic variability raises the question as to the cause and effect in this relationship. Kang and Polvani (2011) posed a similar question, but their focus was mainly on whether the variability in the position of the midlatitude (eddy driven) jet and the variability of the edge of the tropical circulation were related to each other on interannual time scales. By contrast, we are interested in their relationship on the finer time scale.

To address this question, we display in Fig. 8 the lag correlation between the STR location/intensity and the number of fronts over the $\mathrm{SH}$ and in each sector. Note here that fronts were not considered in the $20^{\circ}-40^{\circ} \mathrm{S}$ band, as in some of the previous figures, but rather across the whole midlatitude domain (south of $20^{\circ} \mathrm{S}$ ) in the selected regions. The analysis is performed on synoptic time steps (every 6h). Although correlation coefficients are low ( 0.1 for the STR location and between 0.1 and 0.3 for the STR intensity), the relationship is highly significant $(p<0.01)$ due to the large sample size. For the STR position (Fig. 8, left panels), the correlation coefficients reach their maximum at 0.5-2 days lag time, which indicates that the changes in the number of fronts lead the shift in the STR location. It is worth noting that 


\section{a) annual}

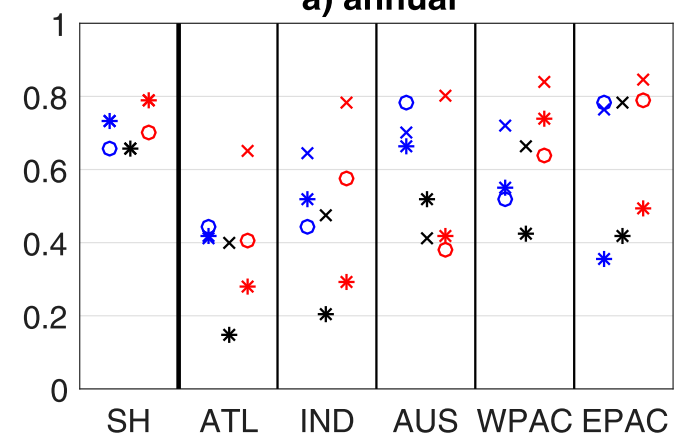

- STRP / frN

$\times$ STRP / (-1)SAM

* STRP / (-1)SH SAM

- (-1)STRI / frN

$\times \quad$ STRI / SAM

* STRI / SH SAM

$\times \mathrm{frN} /(-1)$ SAM

* $\mathrm{frN} /(-1) \mathrm{SH}$ SAM

b) DJF

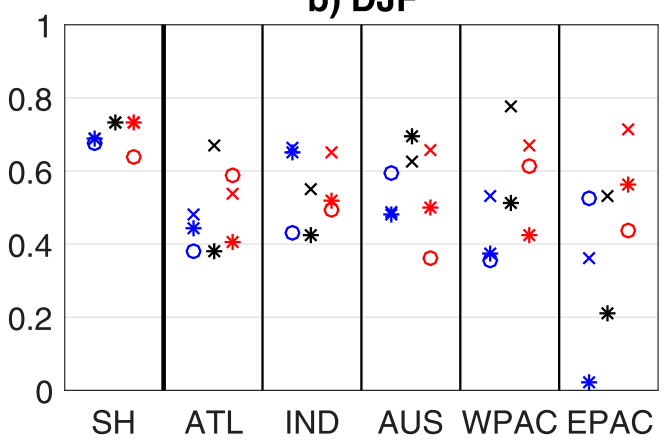

d) JJA

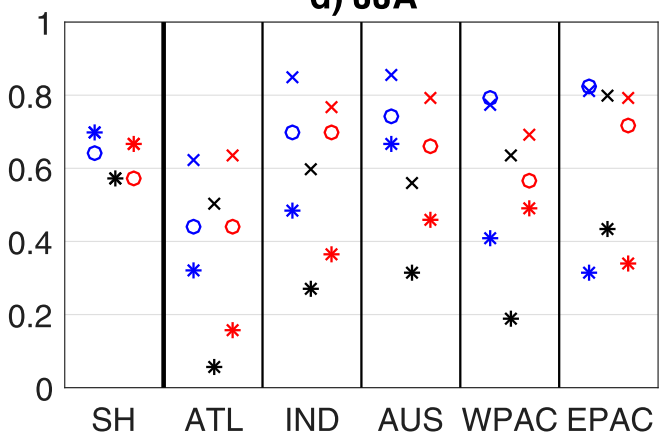

c) MAM

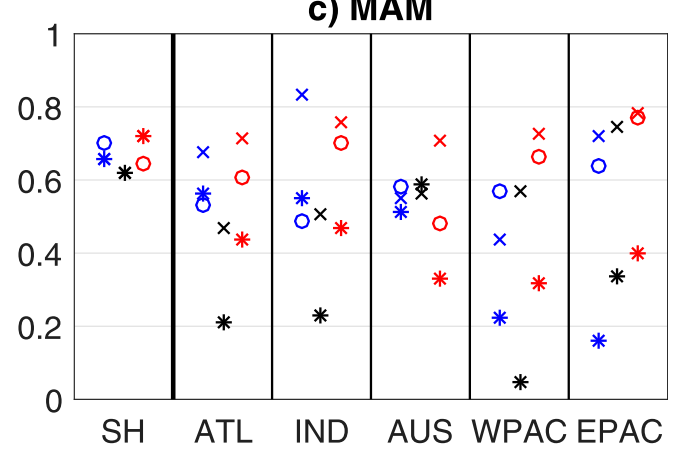

e) SON

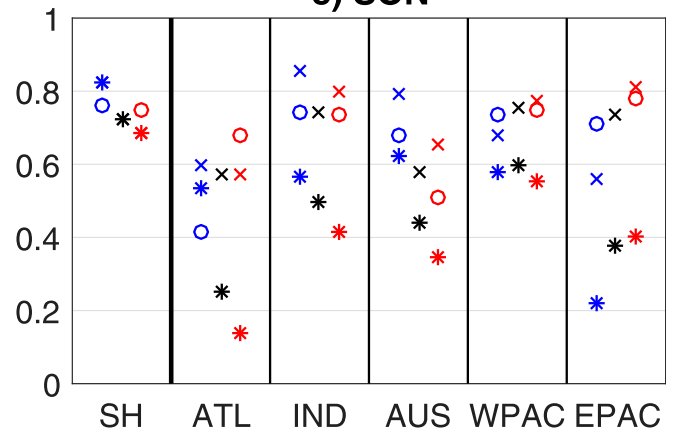

FIG. 5. Correlation coefficients (circles) between the STR position (blue) or STR intensity (red) and the number of fronts between $20^{\circ}$ and $40^{\circ} \mathrm{S}$ for the $\mathrm{SH}$ and individually for the five sectors. Crosses show correlations with the regional SAM indices, and asterisks indicate correlations with the SH (zonal mean) SAM. Note that some indices are multiplied by -1 to yield positive correlations, as indicated in the legend.

fronts, as defined here, are attributed to a time step $t$ when the wind shift takes place between $t$ and $t+6 \mathrm{~h}$. Taking into account that frontogenesis also takes some time to occur, we conclude that changes in the midlatitude circulation lead the shift in the STR location by at least 1 day. This statement holds for the SH and most of the sectors considered, with perhaps the exception of the EPAC where the circulation is closely linked to tropical SST anomalies as discussed in the previous section.

As for the STR intensity, Figs. 8f-j show simultaneous changes in the number of fronts and STR intensity (i.e., lag 0), in all sectors except AUS. Indeed, in the Australian sector an intensification of the STR results in a reduction of the number of fronts in approximately half a day. This may be a result of the formation of blocking highs over the Great Australian Bight (Jones and Simmonds 1994), which tend to interact with the STR, affecting its intensity and blocking the west-to-east progression of weather systems in that sector. Although anticyclones also form between $30^{\circ}$ and $40^{\circ} \mathrm{S}$ in other sectors of the $\mathrm{SH}$, particularly over the Indian Ocean (Pepler et al. 2019), the proposed mechanism would be more influential in the AUS region where the STR is 
a) annual

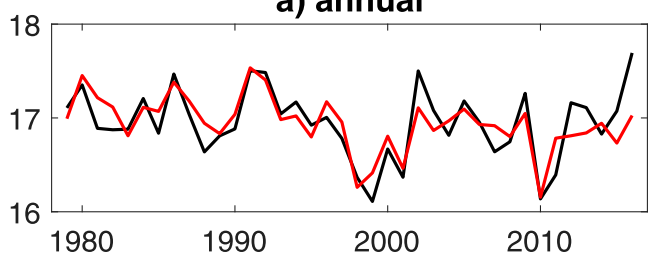

b) DJF
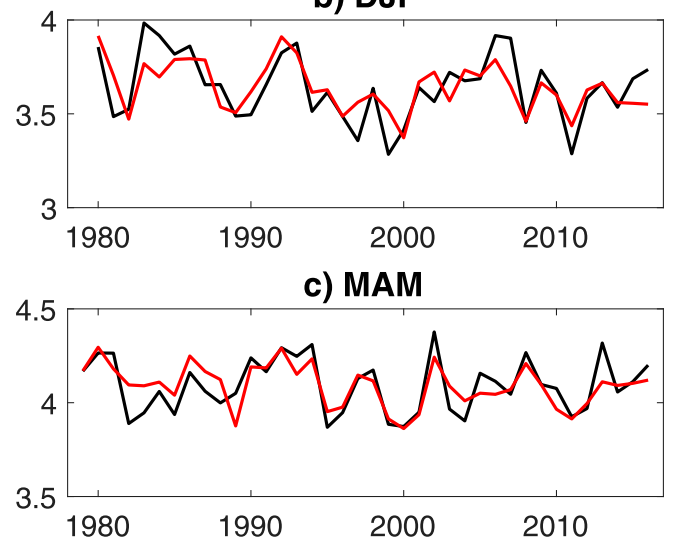

d) JJA

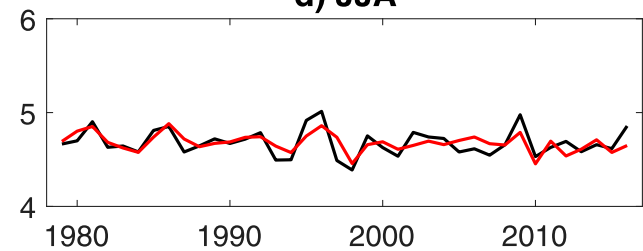

e) SON

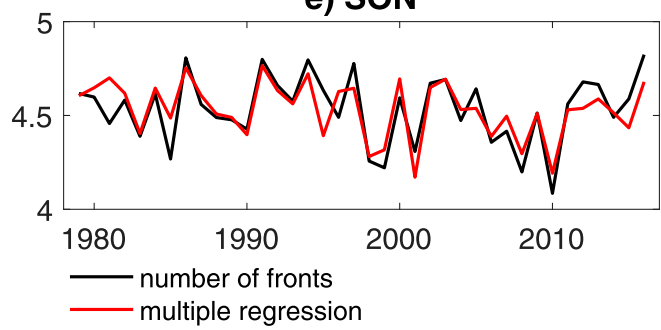

f) annual

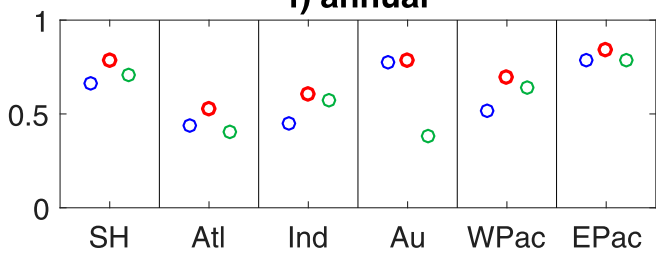

g) DJF

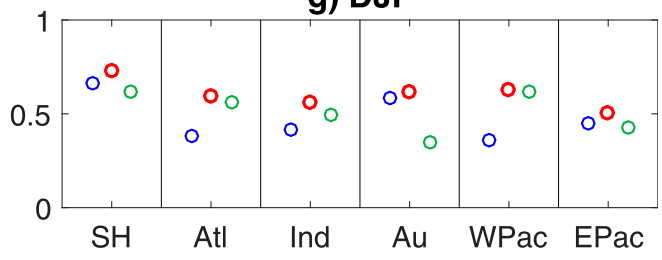

h) MAM

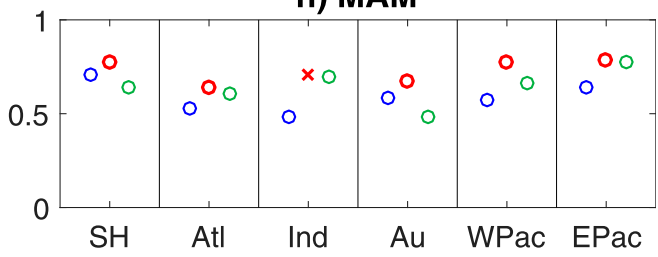

i) JJA

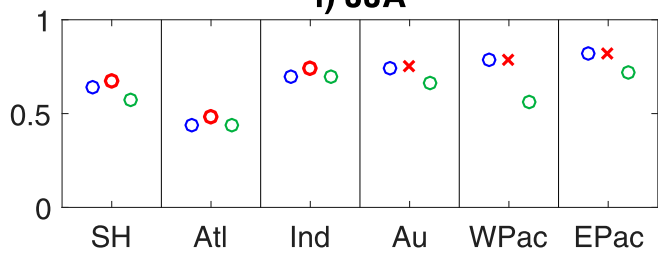

j) SON

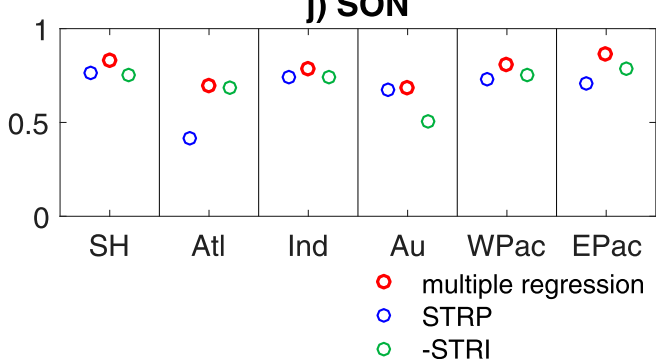

FIG. 6. Multiple linear regression of the response in the number of fronts between $20^{\circ}$ and $40^{\circ} \mathrm{S}$ to variations in the STR position and STR intensity in the SH: (a)-(e) time series of the number of fronts (black) and the fitted line (red), and (f)-(j) correlation of the number of fronts between $20^{\circ}-40^{\circ} \mathrm{S}$ with linear fit (red), STR position (blue), and $-1 \times$ STR intensity (green) in the SH and in each of the five regions. Crosses indicate cases in which adding the second predictor does not improve the model as revealed by the adjusted $R^{2}$.

located farther poleward than average, especially in the warmer months (also confirmed by PSI analysis in NG2018). This conclusion is supported by the fact that in winter, when the STR is shifted equatorward, the lag between the STR intensity and the number of fronts almost disappears. This proposed mechanism comes with the caveat that the interaction of synoptic-scale highs and lows is complex, and intrinsically linked to the behavior of the midlatitude jet stream. This complexity is reflected by the highly statistically significant, albeit modest, correlation coefficient values above.

\section{Conclusions}

The aim of this study was to examine the relationship between midlatitude synoptic activity and the width of the tropics in the SH. The edge of the tropical belt in the $\mathrm{SH}$ is generally in good agreement with the location of the STR as shown by Waugh et al. (2018). For the eddy 
a) STRP max-min, SH

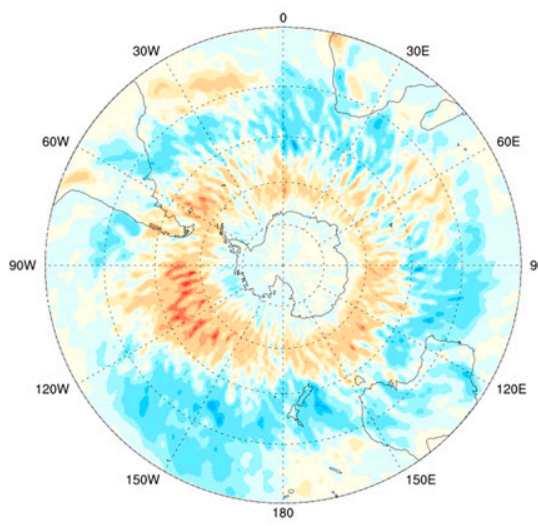

b) STRP max-min, IND

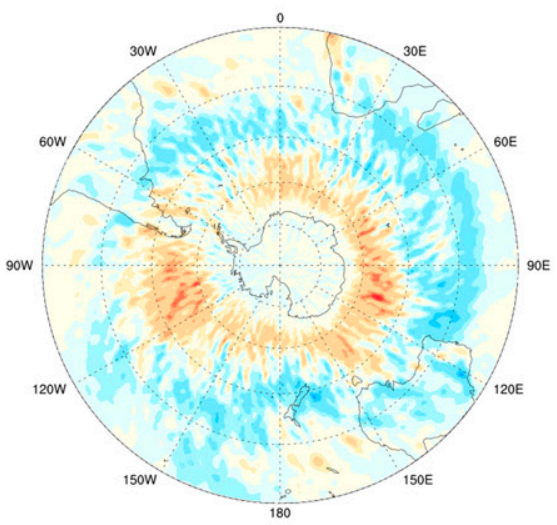

c) STRP max-min, EPAC

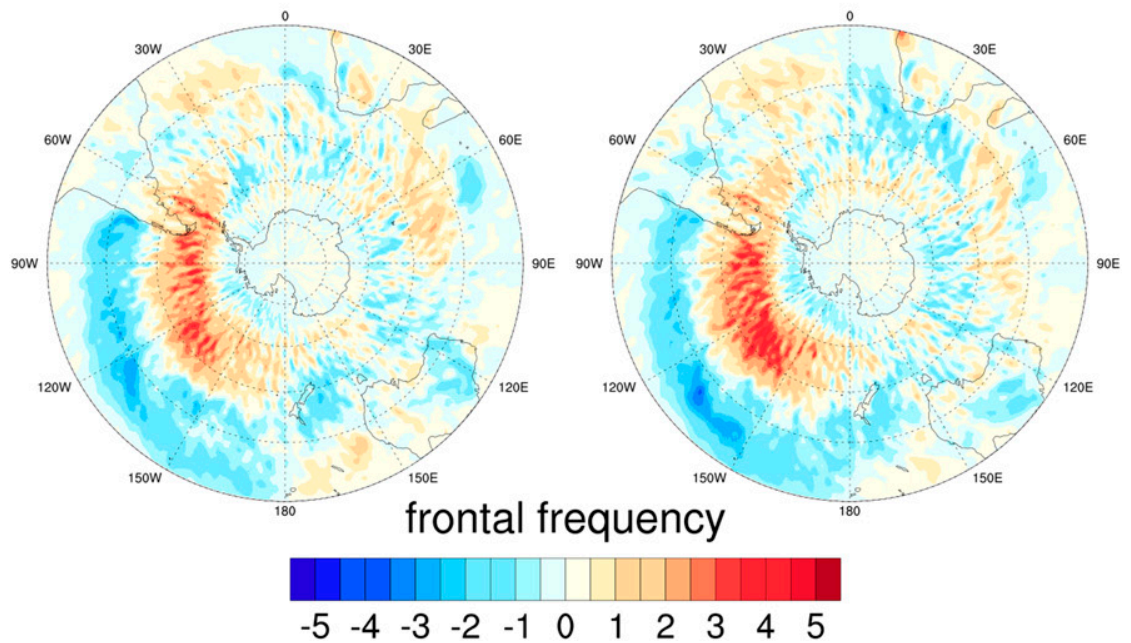

FIG. 7. Differences between the average annual number of fronts for 10 years of (a)-(c) the most poleward and most equatorward position and (d)-(f) the highest and lowest intensity of the STR for the (top) SH, (middle) IND, and (bottom) EPAC sectors. activity in the midlatitudes, a Lagrangian approach was used by considering frontal structures. Our analysis was limited to cold front behavior; however, in a broader sense, the number of warm fronts is proportional to the number of cold fronts (Schemm et al. 2015) and, thus, the conclusions derived here should also be valid for overall frontal activity. Our analysis, based on objectively identified fronts in ERA-Interim, has shown that 
a) STRP, annual

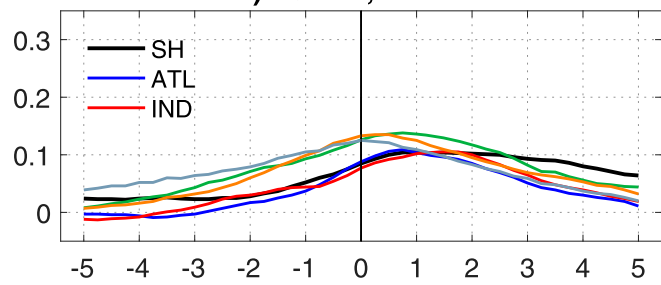

b) DJF

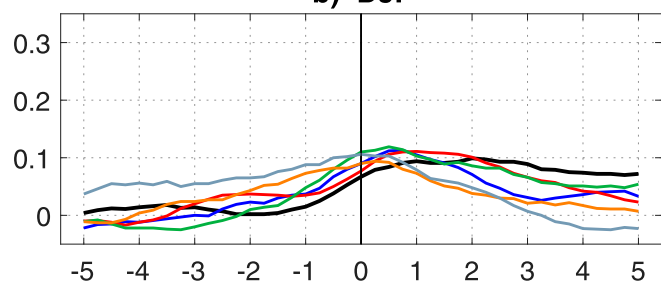

c) MAM

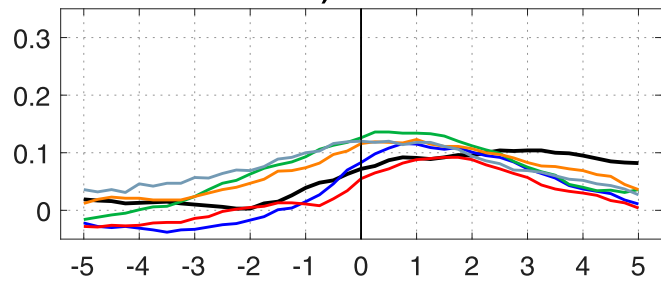

d) JJA

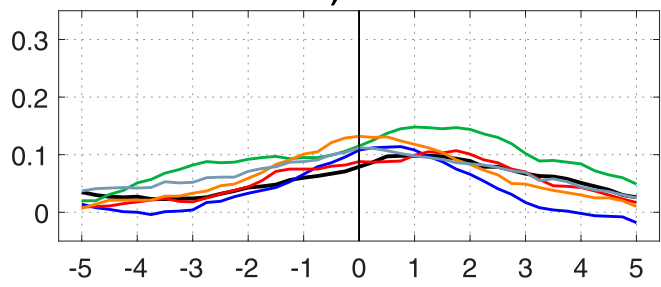

e) SON

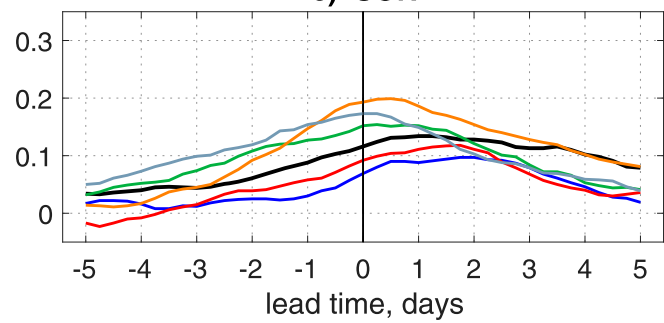

f) $(-1)^{\star}$ STRI, annual

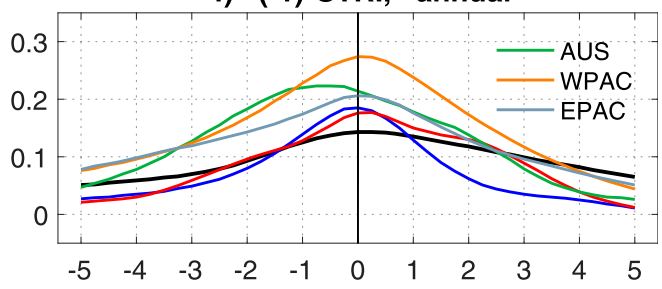

g) DJF

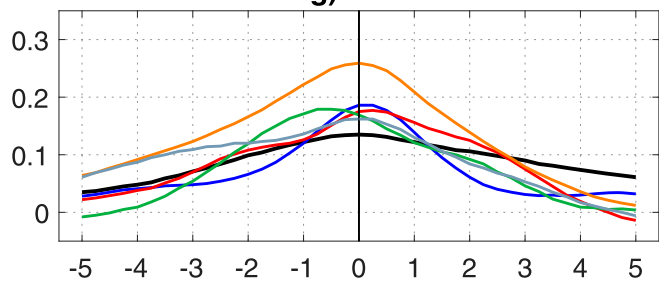

h) MAM

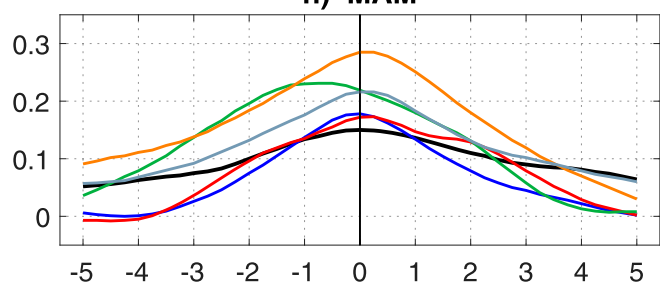

i) JJA

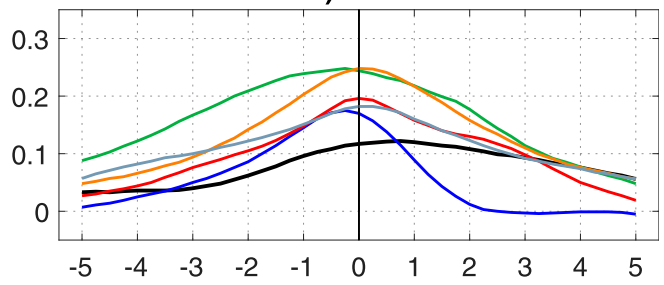

j) SON

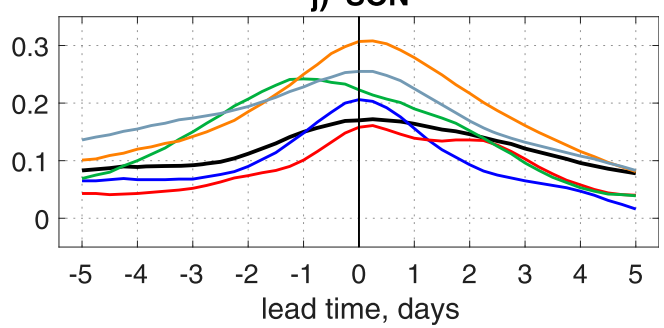

FIG. 8. Lag correlation between the number of fronts in the SH and STR (left) position and (right) intensity. Positive or negative lag time indicates that the number of fronts leads or lags, respectively, the changes in STR characteristics.

the number of fronts is strongly correlated with the location and intensity of the STR.

Despite the overall high agreement between the number of atmospheric fronts and STR characteristics in the $\mathrm{SH}$, on the regional scale there are a few processes that may affect variability in both the STR and synoptic activity in midlatitudes, as well as the link between them:
- The Atlantic and Australian sectors show opposing tendencies in the summer STR behavior-in the Australian region the STR is located poleward relative to the zonally average position because of the strong meridional temperature gradient on its southern flank, whereas over the Atlantic the STR is shifted equatorward relative to the other regions. Therefore, in the Australian sector the fronts in low midlatitudes 
are mainly linked to the STR position while in the Atlantic the STR intensity plays a more important role throughout the year, except during winter.

- In the Indian Ocean the atmospheric circulation is characterized by a more zonally symmetric pattern than in the other oceans, which leads to weak interseasonal variations in the STR position and higher values of STR intensity. Our results suggest a moderate link between frontal variability and STR characteristics. Moreover, the correlation between the SAM and the STR location shows the highest values when compared with other ocean regions.

- In the western Pacific the number of fronts during summer and spring is strongly associated with the SAM, whereas in other seasons the strong subtropical jet isolates the tropics from the extratropics, minimizing the effect of the SAM on the tropical width (Hendon et al. 2014). On the other hand, in the eastern Pacific the variability in the number of fronts is weakly correlated with both the SAM and the STR in the warm season, because this region is strongly influenced by a Rossby wave train forced by SST anomalies in the equatorial central-eastern Pacific (Ding et al. 2012). The number of fronts in this region is strongly associated with the STR location during winter [as opposed to the conclusions reached by Kang and Polvani (2011)] and is strongly linked to its intensity in spring.

To further understand the close link between the seasonal characteristics of midlatitude synoptic systems and the tropical extent, we also examined their relationship on the synoptic time scale. We found that the variability in the STR position is driven by the changes in midlatitude synoptic activity, which occur at least one day ahead of the corresponding shift in the STR position. Although the correlation between the STR location and the number of fronts is low, it is statistically significant and very robust throughout the year and is observed in all regions of the $\mathrm{SH}$ (except the EPAC sector). Levine and Schneider (2015) stated that the Hadley circulation terminates where baroclinic eddies start controlling the dynamics, which is in agreement with the "seamless" energy transport shown by Trenberth and Stepaniak (2003). The lagged response of the STR to changes in frontal activity found in this paper corroborates the idea of baroclinic eddies being responsible for changes in tropical extent.

However, our conclusion of eddy-driven variability influencing tropical width would also need to be tested using other definitions of tropical extent. As various tropical width diagnostics reflect different physical processes, they might demonstrate somewhat different relationships not only with the midlatitude eddy activity but also with each other when analyzed at finer time scales. To date, the relationship between tropical width diagnostics, as well as the variability of tropical width, has been analyzed on the seasonal time scale (Grise et al. 2018; Staten et al. 2018). It will be of interest to investigate these processes on the synoptic time scale to better understand the mechanisms driving changes in the circulation at both tropical and midlatitudes.

Acknowledgments. We thank the three anonymous reviewers for their reviews, which provided new insight and very detailed comments that improved the clarity of the paper. We thank the European Centre for Medium-Range Weather Forecasts for the atmospheric reanalysis data. Parts of this work were made possible by a grant from the Australian Research Council (DP160101997). Irina Rudeva also benefited from project 14.613.21.0083 (ID RFMEFI61317 × 0083) with the Ministry of Education and Science of Russian Federation. Ghyslaine Boschat was supported by the ARC Centre of Excellence for Climate Extremes (Grant CE170100023).

\section{REFERENCES}

Allen, R. J., and M. Kovilakam, 2017: The role of natural climate variability in recent tropical expansion. J. Climate, 30, 63296350, https://doi.org/10.1175/JCLI-D-16-0735.1.

Amaya, D. J., N. Siler, S.-P. Xie, and A. J. Miller, 2018: The interplay of internal and forced modes of Hadley cell expansion: Lessons from the global warming hiatus. Climate Dyn., 51, 305-319, https://doi.org/10.1007/s00382-017-3921-5.

Baker, H. S., C. Mbengue, and T. Woollings, 2018: Seasonal sensitivity of the Hadley cell and cross-hemispheric responses to diabatic heating in an idealized GCM. Geophys. Res. Lett., 45, 2533-2541, https://doi.org/10.1002/2018GL077013.

Berry, G., C. Jakob, and M. Reeder, 2011: Recent global trends in atmospheric fronts. Geophys. Res. Lett., 38, L21812, https:// doi.org/10.1029/2011GL049481.

Birner, T., S. M. Davis, and D. J. Seidel, 2014: The changing width of Earth's tropical belt. Phys. Today, 67, 38-44, https://doi.org/ 10.1063/PT.3.2620.

Blázquez, J., and S. A. Solman, 2018: Fronts and precipitation in CMIP5 models for the austral winter of the Southern Hemisphere. Climate Dyn., 50, 2705-2717, https://doi.org/10.1007/ s00382-017-3765-z.

Byrne, M. P., and T. Schneider, 2016: Energetic constraints on the width of the intertropical convergence zone. J. Climate, 29, 4709-4721, https://doi.org/10.1175/JCLI-D-15-0767.1.

Cai, W., and T. Cowan, 2013: Southeast Australia autumn rainfall reduction: A climate-change-induced poleward shift of oceanatmosphere circulation. J. Climate, 26, 189-205, https://doi.org/ 10.1175/JCLI-D-12-00035.1.

_ - _ and M. Thatcher, 2012: Rainfall reductions over Southern Hemisphere semi-arid regions: The role of subtropical dry zone expansion. Sci. Rep., 2, 702, https://doi.org/ 10.1038/srep00702. 
Catto, J. L., N. Nicholls, C. Jakob, and K. L. Shelton, 2014: Atmospheric fronts in current and future climates. Geophys. Res. Lett., 41, 7642-7650, https://doi.org/10.1002/2014GL061943.

Chang, E. K. M., 2017: Projected significant increase in the number of extreme extratropical cyclones in the Southern Hemisphere. J. Climate, 30, 4915-4935, https://doi.org/ 10.1175/JCLI-D-16-0553.1.

Choi, J., S.-W. Son, J. Lu, and S.-K. Min, 2014: Further observational evidence of Hadley cell widening in the Southern Hemisphere. Geophys. Res. Lett., 41, 2590-2597, https:// doi.org/10.1002/2014GL059426.

Collins, M., and Coauthors, 2013: Long-term climate change: Projections, commitments and irreversibility. Climate Change 2013: The Physical Science Basis, T. F. Stocker et al., Eds., Cambridge University Press, 1029-1136.

Crespo, J. A., D. J. Posselt, C. M. Naud, and C. Bussy-Virat, 2017: Assessing CYGNSS's potential to observe extratropical fronts and cyclones. J. Appl. Meteor. Climatol., 56, 2027-2034, https://doi.org/10.1175/JAMC-D-17-0050.1.

D'Agostino, R., and P. Lionello, 2017: Evidence of global warming impact on the evolution of the Hadley Circulation in ECMWF centennial reanalyses. Climate Dyn., 48, 3047-3060, https:// doi.org/10.1007/s00382-016-3250-0.

Davis, N., and T. Birner, 2017: On the discrepancies in tropical belt expansion between reanalyses and climate models and among tropical belt width metrics. J. Climate, 30, 1211-1231, https:// doi.org/10.1175/JCLI-D-16-0371.1.

Davis, S. M., and K. H. Rosenlof, 2012: A multidiagnostic intercomparison of tropical-width time series using reanalyses and satellite observations. J. Climate, 25, 1061-1078, https:// doi.org/10.1175/JCLI-D-11-00127.1.

_ B. Bassler, and K. H. Rosenlof, 2018: Revisiting ozone measurements as an indicator of tropical width. Prog. Earth Planet. Sci., 5, 56, https://doi.org/10.1186/s40645-018-0214-5.

Dee, D. P., and Coauthors, 2011: The ERA-Interim reanalysis: Configuration and performance of the data assimilation system. Quart. J. Roy. Meteor. Soc., 137, 553-597, https://doi.org/10.1002/qj.828.

Ding, Q., E. J. Steig, D. S. Battisti, and J. M. Wallace, 2012: Influence of the tropics on the southern annular mode. J. Climate, 25, 6330-6348, https://doi.org/10.1175/JCLI-D-1100523.1.

Drosdowsky, W., 2005: The latitude of the subtropical ridge over Eastern Australia: The $L$ index revisited. Int. J. Climatol., 25, 1291-1299, https://doi.org/10.1002/joc.1196.

Frederiksen, C. S., and S. Grainger, 2015: The role of external forcing in prolonged trends in Australian rainfall. Climate Dyn., 45, 2455-2468, https://doi.org/10.1007/s00382-015-2482-8.

Fyfe, J. C., 2003: Extratropical Southern Hemisphere cyclones: Harbingers of climate change? J. Climate, 16, 2802-2805, https:// doi.org/10.1175/1520-0442(2003)016<2802:ESHCHO >2.0.CO;2.

Gong, D., and S. Wang, 1999: Definition of Antarctic oscillation index. Geophys. Res. Lett., 26, 459-462, https://doi.org/10.1029/ 1999GL900003.

Grieger, J., G. C. Leckebusch, C. C. Raible, I. Rudeva, and I. Simmonds, 2018: Subantarctic cyclones identified by 14 tracking methods, and their role for moisture transports into the continent. Tellus, 70A, 1454808, https://doi.org/10.1080/ 16000870.2018.1454808.

Grise, K. M., and L. M. Polvani, 2016: Is climate sensitivity related to dynamical sensitivity? J. Geophys. Res., 121, 5159-5176, https://doi.org/10.1002/2015JD024687.

— S. M. Davis, P. W. Staten, and O. Adam, 2018: Regional and seasonal characteristics of the recent expansion of the tropics.
J. Climate, 31, 6839-6856, https://doi.org/10.1175/JCLI-D-180060.1 .

_ and Coauthors, 2019: Recent tropical expansion: Natural variability or forced response? J. Climate, 32, 1551-1571, https://doi.org/10.1175/JCLI-D-18-0444.1.

Hendon, H. H., E.-P. Lim, and H. Nguyen, 2014: Seasonal variations of subtropical precipitation associated with the southern annular mode. J. Climate, 27, 3446-3460, https://doi.org/ 10.1175/JCLI-D-13-00550.1.

Hodges, K. I., R. W. Lee, and L. Bengtsson, 2011: A comparison of extratropical cyclones in recent reanalyses ERA-Interim, NASA MERRA, NCEP CFSR, and JRA-25. J. Climate, 24, 4888-4906, https://doi.org/10.1175/2011JCLI4097.1.

Hope, P., W. Drosdowsky, and N. Nicholls, 2006: Shifts in synoptic systems influencing southwest Western Australia. Climate Dyn., 26, 751-764, https://doi.org/10.1007/s00382-006-0115-y.

— front recognition for climate studies: A case study in southwest Western Australia. Mon. Wea. Rev., 142, 343-363, https:// doi.org/10.1175/MWR-D-12-00252.1.

Jones, D. A., and I. Simmonds, 1994: A climatology of Southern Hemisphere anticyclones. Climate Dyn., 10, 333-348, https:// doi.org/10.1007/BF00228031.

Kang, S. M., and L. M. Polvani, 2011: The interannual relationship between the latitude of the eddy-driven jet and the edge of the Hadley cell. J. Climate, 24, 563-568, https://doi.org/10.1175/ 2010JCLI4077.1.

Kent, D. M., D. G. C. Kirono, B. Timbal, and F. H. S. Chiew, 2013: Representation of the Australian sub-tropical ridge in the CMIP3 models. Int. J. Climatol., 33, 48-57, https://doi.org/ 10.1002/joc.3406

Kidston, J., J. A. Renwick, and J. McGregor, 2009: Hemisphericscale seasonality of the southern annular mode and impacts on the climate of New Zealand. J. Climate, 22, 4759-4770, https:// doi.org/10.1175/2009JCLI2640.1.

Kim, Y.-H., S.-K. Min, S.-W. Son, and J. Choi, 2017: Attribution of the local Hadley cell widening in the Southern Hemisphere. Geophys. Res. Lett., 44, 1015-1024, https://doi.org/10.1002/ 2016 GL072353.

Kirtman, B., and Coauthors, 2013: Near-term climate change: Projections and predictability. Climate Change 2013: The Physical Science Basis, T. F. Stocker et al., Eds., Cambridge University Press, 953-1028.

Levine, X. J., and T. Schneider, 2015: Baroclinic eddies and the extent of the Hadley circulation: An idealized GCM study. J. Atmos. Sci., 72, 2744-2761, https://doi.org/10.1175/JAS-D-14-0152.1.

Li, Y., J. P. Li, and J. Feng, 2012: A teleconnection between the reduction of rainfall in southwest Western Australia and North China. J. Climate, 25, 8444-8461, https://doi.org/ 10.1175/JCLI-D-11-00613.1.

Lucas, C., and H. Nguyen, 2015: Regional characteristics of tropical expansion and the role of climate variability. J. Geophys. Res., 120, 6809-6824, https://doi.org/10.1002/2015JD023130.

MacKellar, N., M. New and C. Jack, 2014: Observed and modelled trends in rainfall and temperature for South Africa: 19602010. S. African J. Sci., 110, 51-63, https://doi.org/10.1590/ SAJS.2014/20130353.

Maher, P., and S. C. Sherwood, 2016: Skill in simulating Australian precipitation at the tropical edge. J. Climate, 29, 1477-1496, https://doi.org/10.1175/JCLI-D-15-0548.1.

Mantsis, D. F., S. Sherwood, R. Allen, and L. Shi, 2017: Natural variations of tropical width and recent trends. Geophys. Res. Lett., 44, 3825-3832, https://doi.org/10.1002/2016GL072097. 
Marshall, G. J., 2003: Trends in the southern annular mode from observations and reanalyses. J. Climate, 16, 4134-4143, https:// doi.org/10.1175/1520-0442(2003)016<4134:TITSAM>2.0.CO;2.

Mbengue, C., and T. Schneider, 2017: Storm-track shifts under climate change: Toward a mechanistic understanding using baroclinic mean available potential energy. J. Atmos. Sci., 74, 93-110, https://doi.org/10.1175/JAS-D-15-0267.1.

_ , and - 2018: Linking Hadley circulation and storm tracks in a conceptual model of the atmospheric energy balance. J. Atmos. Sci., 75, 841-856, https://doi.org/10.1175/JAS-D-170098.1.

Meneghini, B., I. Simmonds, and I. N. Smith, 2007: Association between Australian rainfall and the southern annular mode. Int. J. Climatol., 27, 109-121, https://doi.org/10.1002/joc.1370.

Newman, M., and Coauthors, 2016: The Pacific decadal oscillation, revisited. J. Climate, 29, 4399-4427, https://doi.org/10.1175/ JCLI-D-15-0508.1.

Nguyen, H., A. Evans, C. Lucas, I. Smith, and B. Timbal, 2013: The Hadley circulation in reanalyses: Climatology, variability and change. J. Climate, 26, 3357-3376, https://doi.org/10.1175/ JCLI-D-12-00224.1.

- , H. H. Hendon, E.-P. Lim, G. Boschat, E. Maloney, and B. Timbal, 2018: Variability of the extent of the Hadley circulation in the Southern Hemisphere: A regional perspective. Climate Dyn., 50, 129-142, https://doi.org/10.1007/s00382-0173592-2.

Oort, A. H., and J. J. Yienger, 1996: Observed interannual variability in the Hadley circulation and its connection to ENSO. J. Climate, 9, 2751-2767, https://doi.org/10.1175/ 1520-0442(1996)009<2751:OIVITH >2.0.CO;2.

Parfitt, R., A. Czaja, and H. Seo, 2017: A simple diagnostic for the detection of atmospheric fronts. Geophys. Res. Lett., 44, 43514358, https://doi.org/10.1002/2017GL073662.

Pepler, A., A. Dowdy, and P. Hope, 2019: A global climatology of surface anticyclones, their variability, associated drivers and long-term trends. Climate Dyn., 52, 5397-5412, https://doi.org/ 10.1007/S00382-018-4451-5.

Pezza, A. B., I. Simmonds, and J. A. Renwick, 2007: Southern Hemisphere cyclones and anticyclones: Recent trends and links with decadal variability in the Pacific Ocean. Int. J. Climatol., 27, 1403-1419, https://doi.org/10.1002/joc.1477.

_- H. Rashid, and I. Simmonds, 2012: Climate links and recent extremes in Antarctic sea ice, high-latitude cyclones, southern annular mode and ENSO. Climate Dyn., 38, 57-73, https:// doi.org/10.1007/s00382-011-1044-y.

Purich, A., T. Cowan, S. Min, and W. Cai, 2013: Autumn precipitation trends over Southern Hemisphere midlatitudes as simulated by CMIP5 models. J. Climate, 26, 8341-8356, https:// doi.org/10.1175/JCLI-D-13-00007.1.

Quan, X.-W., M. P. Hoerling, J. Perlwitz, H. F. Diaz, and T. Y. Xu, 2014: How fast are the tropics expanding? J. Climate, 27, 19992013, https://doi.org/10.1175/JCLI-D-13-00287.1.

Randall, D. A., 2015: An Introduction to the Global Circulation of the Atmosphere. Princeton University Press, $456 \mathrm{pp}$.

Raut, B. A., M. J. Reeder, and C. Jakob, 2017: Trends in CMIP5 rainfall patterns over southwestern Australia. J. Climate, 30, 1779-1788, https://doi.org/10.1175/JCLI-D-16-0584.1.

Risbey, J. S., M. J. Pook, P. C. McIntosh, M. C. Wheeler, and H. H. Hendon, 2009: On the remote drivers of rainfall variability in Australia. Mon. Wea. Rev., 137, 3233-3253, https://doi.org/ 10.1175/2009MWR2861.1.

Rudeva, I., and I. Simmonds, 2015: Variability and trends of global atmospheric frontal activity and links with large-scale modes of variability. J. Climate, 28, 3311-3330, https://doi.org/ 10.1175/JCLI-D-14-00458.1.

Schemm, S., I. Rudeva, and I. Simmonds, 2015: Extratropical fronts in the lower troposphere: Global perspectives obtained from two automated methods. Quart. J. Roy. Meteor. Soc., 141, 1686-1698, https://doi.org/10.1002/qj.2471.

Schmidt, D. F., and K. M. Grise, 2017: The response of local precipitation and sea level pressure to Hadley cell expansion. Geophys. Res. Lett., 44, 10 573-10 582, https://doi.org/10.1002/ 2017GL075380.

Shaw, T. A., and A. Voigt, 2016: What can moist thermodynamics tell us about circulation shifts in response to uniform warming? Geophys. Res. Lett., 43, 4566-4575, https://doi.org/ 10.1002/2016GL068712.

Simmonds, I., and K. Keay, 2000: Variability of Southern Hemisphere extratropical cyclone behavior 1958-97. J. Climate, 13, 550-561, https://doi.org/10.1175/1520-0442(2000)013<0550: VOSHEC $>2.0 . \mathrm{CO} ; 2$.

, — , and J. A. T. Bye, 2012: Identification and climatology of Southern Hemisphere mobile fronts in a modern reanalysis. J. Climate, 25, 1945-1962, https://doi.org/10.1175/JCLI-D-11-00100.1.

Singh, M. S., and Z. Kuang, 2016: Exploring the role of eddy momentum fluxes in determining the characteristics of the equinoctial Hadley circulation: Fixed-SST simulations. J. Atmos. Sci., 73, 2427-2444, https://doi.org/10.1175/JAS-D-15-0212.1.

,-- , and Y. Tian, 2017: Eddy influences on the strength of the Hadley circulation: Dynamic and thermodynamic perspectives. J. Atmos. Sci., 74, 467-486, https://doi.org/10.1175/ JAS-D-16-0238.1.

Solman, S. A., and I. Orlanski, 2014: Poleward shift and change of frontal activity in the Southern Hemisphere over the last 40 years. J. Atmos. Sci., 71, 539-552, https://doi.org/10.1175/JASD-13-0105.1.

— and - 2016: Climate change over the extratropical Southern Hemisphere: The tale from an ensemble of reanalysis datasets. J. Climate, 29, 1673-1687, https://doi.org/ 10.1175/JCLI-D-15-0588.1.

Solomon, A., L. M. Polvani, D. W. Waugh, and S. M. Davis, 2016: Contrasting upper and lower atmospheric metrics of tropical expansion in the Southern Hemisphere. Geophys. Res. Lett., 43, 10 496-10 503, https://doi.org/10.1002/2016GL070917.

Son, S.-W., S.-Y. Kim, and S.-K. Min, 2018: Widening of the Hadley cell from Last Glacial Maximum to future climate. J. Climate, 31, 267-281, https://doi.org/10.1175/JCLI-D-17-0328.1.

Spensberger, C., and M. Sprenger, 2018: Beyond cold and warm: An objective classification for maritime midlatitude fronts. Quart. J. Roy. Meteor. Soc., 144, 261-277, https://doi.org/ 10.1002/qj.3199.

Staten, P. W., J. Lu, K. M. Grise, S. M. Davis, and T. Birner, 2018: Re-examining tropical expansion. Nat. Climate Change, 8 , 768-775, https://doi.org/10.1038/s41558-018-0246-2.

Tamarin, T., and Y. Kaspi, 2017: The poleward shift of storm tracks under global warming: A Lagrangian perspective. Geophys. Res. Lett., 44, 10 666-10 674, https://doi.org/10.1002/2017GL073633.

Tamarin-Brodsky, T., and Y. Kaspi, 2017: Enhanced poleward propagation of storms under climate change. Nat. Geosci., 10, 908-913, https://doi.org/10.1038/s41561-017-0001-8.

Tao, L., Y. Hu, and J. Liu, 2016: Anthropogenic forcing on the Hadley circulation in CMIP5 simulations. Climate Dyn., 46, 3337-3350, https://doi.org/10.1007/s00382-015-2772-1.

Taylor, K. E., R. J. Stouffer, and G. A. Meehl, 2012: An overview of CMIP5 and the experiment design. Bull. Amer. Meteor. Soc., 93, 485-498, https://doi.org/10.1175/BAMS-D-11-00094.1. 
Thompson, D. W. J., and J. M. Wallace, 2000: Annular modes in the extratropical circulation. Part I: Month-to-month variability. J. Climate, 13, 1000-1016, https://doi.org/10.1175/15200442(2000)013<1000:AMITEC > 2.0.CO;2.

Tilinina, N., S. K. Gulev, I. Rudeva, and P. Koltermann, 2013: Comparing cyclone life cycle characteristics and their interannual variability in different reanalyses. J. Climate, 26, 6419-6438, https://doi.org/10.1175/JCLI-D-12-00777.1.

Timbal, B., and W. Drosdowsky, 2013: The relationship between the decline of southeastern Australian rainfall and the strengthening of the subtropical ridge. Int. J. Climatol., 33, 1021-1034, https://doi.org/10.1002/joc.3492.

Trenberth, K. E., and D. P. Stepaniak, 2003: Seamless poleward atmospheric energy transports and implications for the Hadley circulation. J. Climate, 16, 3706-3722, https://doi.org/ 10.1175/1520-0442(2003)016<3706:SPAETA > 2.0.CO;2.

, and - 2004: The flow of energy through the Earth's climate system. Quart. J. Roy. Meteor. Soc., 130, 2677-2701, https://doi.org/10.1256/qj.04.83.

Turton, S. M., 2017: Expansion of the tropics: Revisiting frontiers of geographical knowledge. Geogr. Res., 55, 3-12, https:// doi.org/10.1111/1745-5871.12230.
Venables, W. N., and B. D. Ripley, 2003: Modern Applied Statistics with $S$ (Statistics and Computing). Springer, $498 \mathrm{pp}$.

Waugh, D. W., and Coauthors, 2018: Revisiting the relationship among metrics of tropical expansion. J. Climate, 31, 75657581, https://doi.org/10.1175/JCLI-D-18-0108.1.

Wernli, H., and C. Schwierz, 2006: Surface cyclones in the ERA-40 dataset (1958-2001). Part I: Novel identification method and global climatology. J. Atmos. Sci., 63, 2486-2507, https:// doi.org/10.1175/JAS3766.1.

Whan, K., B. Timbal, and J. Lindesay, 2014: Linear and nonlinear statistical analysis of the impact of sub-tropical ridge intensity and position on south-east Australian rainfall. Int. J. Climatol., 34, 326-342, https://doi.org/10.1002/ joc.3689.

Williams, A. A. J., and R. C. Stone, 2009: An assessment of relationships between the Australian subtropical ridge, rainfall variability, and high-latitude circulation patterns. Int. J. Climatol., 29, 691-709, https://doi.org/10.1002/joc.1732.

Zurita-Gotor, P., and P. Álvarez-Zapatero, 2018: Coupled interannual variability of the Hadley and Ferrel cells. J. Climate, 31, 4757-4773, https://doi.org/10.1175/JCLID-17-0752.1. 